\title{
RESEARCH ON MANUFACTURER ENCROACHMENT WITH ADVERTISING AND DESIGN OF INCENTIVE ADVERTISING: A GAME-THEORETIC APPROACH
}

\author{
JUNHAi MA AND YALAN HONG*
}

\begin{abstract}
This paper studies a supply chain with manufacturer encroachment where both the manufacturer and the retailer invest in advertising to explore the effects of manufacturer encroachment and different quantity decision sequence on advertising strategy and profits for the players. It is known that manufacturer encroachment usually intensifies the completion, which may make the retailer worse off. Our results show that (1) the retailer tends to increase his advertising expenditure under encroachment if manufacturer's direct selling cost increases and the manufacturer may increase that in most cases; (2) the retailer is better off with encroachment when the manufacturer's direct selling cost is high; (3) the manufacturer may benefit from encroachment when his direct selling cost is high or low, which is related with his advertising effectiveness; (4) encroachment may lead to a win-win result, which depends on the relative advertising effectiveness and the manufacturer's direct selling cost. Additionally, we consider two ways of advertising cooperation. Results show that centralized advertising decisionmaking is not always conducive to both firms. If one's advertising effectiveness is relatively high, he can obtain higher profit in the decentralized cooperative advertising program. Usually, the cooperative advertising program is more commonly use. Based on this, we further propose an incentive cooperative advertising scheme which makes all players get higher profits.
\end{abstract}

Mathematics Subject Classification. 91A12, 91A40, 91B24, 90B60.

Received April 27, 2020. Accepted September 2, 2020.

\section{INTRODUCTION}

On account of the convenience of surfing and the popularity of e-commerce, many manufacturers can establish online channels and sell products directly to consumers [15]. Such phenomenon, in general, is termed as "manufacturer encroachment" in various industries. For example, electronic manufacturers, like HP and Apple, and fashion suppliers manufacturers, like Nike and Coach, sell goods through both their agent and their own online stores [10,21]. Batarf et al. [3] pointed out that about $\$ 500$ billion would be spent in direct selling channels in the United States and Canada in 2018. In that case, the direct channel opened by the manufacturer can boost demand and satisfy customers with different preferences. Therefore, the conflicts of distribution channels are no longer limited to the existing traditional channels of selling products through retailers.

\footnotetext{
Keywords. Manufacturer encroachment, advertising, profit improvement, game theory.

College of Management and Economics, Tianjin University, Tianjin 300072, P.R. China.

*Corresponding author: Lena_Hong@tju.edu.cn
} 
Aside from expanding demand by multiple channels, distribution channels put a significant portion of their marketing budget into a variety of non-price marketing campaigns, such as local advertising by retailers and global advertising by manufacturers to promote commodities. With the growing trend of advertising expenditure, further research about advertising is so necessary that higher profits may be achieved. Thus, more comprehensive discussions about advertising and encroachment are needed. Most studies related to advertising have not considered manufacturer encroachment, which investigates advertising strategy channel under different settings (e.g., competitive retailers, information structures and retailer service). Ghadimi et al. [12] study the advertising cooperation in a supply chain with one manufacturer and two retailers to explore the impact of competitive retailers on advertising strategy. Assuming a single distribution channel, Zhang et al. [42] explore how different power structures and information structures affect firms' advertising strategy. Considering the demand uncertainty, Taleizadeh et al. [30] explore the strategy of firms in a single supply chain where the manufacture or the retailer invests in advertising, and use the cost-sharing mechanism to coordinate the system. To our knowledge, few research study the advertising strategy and advertising coordination when the manufacturer has a direct selling channel.

To motivate retailers to invest more in advertising, manufacturers are inclined to share a portion of retailers' advertising expenditures, which is usually called the cooperative advertising program. Since the Warner Brothers Corset Company signed the first cooperative advertising agreement [39], the adoption of cooperative advertising program is on the rise, and it branches out to many industries. Many manufacturers, like HP, Apple and Dell, have been implementing the cooperative advertising program to increase their retailer's advertising expenditure, provoking the instant demand of customers [35]. Moreover, the amount of advertising expenditure is increasing year by year. In terms of quantity, a total sum of $\$ 50$ billion was invested in the cooperative advertising in the United States in 2008 [14]. Hence, it is necessary to study the advertising cooperation to coordinate the supply chain well, especially when the manufacturer encroachment happens.

In this paper, we explore the advertising strategy under the setting of a dual-channel supply chain. Particularly, we investigate the impact of encroachment on advertising decisions and the performance of the firms under different quantity decision sequences. In reality, a variety decision sequences are common, which reflects different power and complicated interdependent relationship in the supply chain. A great number of studies have considered different decision sequences to probe how decision sequence affects the equilibrium strategies of the enterprise $[8,22]$. Considering quality diversity, Ha et al. [13] discovered that the manufacturer is more likely to encroach under simultaneous quantity decision than sequential quantity decision. Whereas, fewer studies have dealt with encroachment and advertising decision under different quantity decision sequence. This paper aims to make contributions to fill the gap. Based on the discussion above, we tend to answer the following question: How does the manufacturer encroachment affect the advertising strategy? What are the effects of encroachment on firms' profits when considering advertising strategy? How does quantity decision structure affects the advertising decision? What are the results of the decision sequence affects the firm's earing? Will the centralized advertising decision-making be better than the cooperative advertising program? Is there any mechanism to further improve the performance of the supply chain under the decentralized setting?

To address these problems, we extend previous scholars' work on advertising $[2,20,33]$ by introducing manufacturer encroachment into the supply chain, where both the manufacturer and the retailer invest in advertising before selling season. At the beginning of the selling season, the retailer determines the order quantity. If the manufacturer encroaches, he also decides the selling quantity in direct channel. To investigate the effect of quantity decision sequence, we construct models under simultaneous and sequential quantity decision when manufacturer encroaches. Additionally, we also propose an incentive cooperative advertising program to further improve the performance of the supply chain. The main findings of our study are as follows: (1) manufacturer encroachment will decrease retail price and wholesale price; (2) the retailer is likely to invest more in his advertising if the manufacturer's direct selling cost is high. Whereas, the manufacturer may increase advertising expense with encroachment in most cases; (3) the manufacturer encroachment may result in a win-win result or win-lose result, which are related with their advertising effectiveness and the direct selling cost; (4) the centralized advertising decision-making is conducive to both the manufacturer and the retailer only when the 
relative advertising effectiveness is within particular region; (5) there exists an incentive cooperative advertising mechanism that can help channel members achieve profit improvement under decentralized advertising decision.

The remainder of this study is organized as follows. Section 2 provides related literature. In Section 3, we develop models with and without encroachment are built and make comparative analysis based on the equilibrium solutions. In Section 4, we consider two different ways of advertising cooperation under manufacturer encroachment and propose an incentive cooperative advertising mechanism. In Section 5, numerical experiments are conducted to illustrate the results intuitively. Section 6 concludes the paper.

\section{Literature REVIEW}

Our study is related with considerable literature which explores manufacturer encroachment under various settings. The phenomenon of manufacturer encroachment has aroused the research interest of many scholars. For example, Yan et al. [36] develop a two-period model to investigate how durability affects the profitability of the supply chain, suggesting that the manufacturer can get higher profits if he only displays product information online but not sells products directly. Assuming that the manufacturer has a direct selling cost, Zhang et al. [40] derive the equilibrium quantity decision and explore the effects of information structures and encroachment. Jafari et al. [17] also consider that the manufacturer has direct selling channel and acquire the optimal pricing decisions to analyze whether firms can benefit from encroachment in a supply chain with multiple retailers. Besides, some other studies suggest that manufacturer encroachment allows firms to invest more in boosting demand to improve the performance of the supply chain [1,7]. Those studies proclaim the fact that manufacturer encroachment is feasible for the supply chain, for players can get higher profits. As far as we know, the advertising strategy under manufacturer encroachment, which may increase demand and improve the performance of the supply chain further, however, has rarely considered.

In addition, our study is also related with studies that investigate the optimal advertising strategy. Considering the effects of different elements, most of previous studies establish the Stackelberg game model to calculate the pricing and advertising strategies. Based on the assumption of Stackelberg game, Aust and Buscher [2] study a single distribution supply chain to derive the optimal pricing and advertising decisions and show the feasibility of cooperation to increase profits. Xie and Wei [33] construct a single channel supply chain to explore the pricing and advertising decisions under cooperative and non-cooperative scenarios. Also, some studies have looked at the exploration of advertising and manufacturer encroachment. Chen [9] studied the pricing strategies and cooperative advertising program of a dual-channel supply chain, indicating that a revenue-sharing mechanism can solve channel conflict. As mentioned before, many pieces of research concentrate their analyses on the determination of the optimal advertising expenditure and pricing to increase profits $[6,12,27]$. To the best of our knowledge, few researches focus on the investigation of quantity decisions and advertising decisions in a dual supply chain. Among the studies of the manufacturer encroachment, quantity decision is a crucial element in supply chain management. Many scholars study the quantity decision in the supply chain $[31,32,40,44]$. To fill the gaps, this paper aims to investigate the advertising and quantity decisions under manufacturer encroachment.

Our paper also relates with studies that explore the effect of the decision timeline on the performance of the supply chain. Distinct decision sequence represents different channel advantages, which may have a marked impact on the performance of the supply chain. Considering the impact of policy, Ma et al. [25] derive the optimal decisions under different pricing time and make comparative analyses, finding that Stackelberg pricing strategy is more conducive to the system stability. Li et al. [21] study equilibrium pricing and reliability enhancement, showing that supplier-leader structure leads to a higher level of investment while it does not bring higher payoff for the supply chain. Ma et al. [24] study how diverse channel power affects the dynamic game characteristics of a dual-channel supply chain. Shoeleh et al. [29] consider five different channel structures to display how the quantity decision and advertising decision influence the performance of the supply chain Seyedesfahani et al. [28] analyze various scenarios of advertising decision including retailer-led manufacturer-led and Nash game to explore how channel power affect the optimal choice of players Similarly Chaab and Rasti-Barzoki [8] taking the cooperative advertising program into consideration explore how the equilibrium solutions vary with different 
game structures Some studies also discuss how the quantity decision sequence affects the players' choice For example Zhang et al. [40] compare the retailer-led quantity decision and the manufacturer-led quantity decision pointing out that the manufacturer has no incentive to make quantity decision firstly Ha et al. [13] analyze the impact of encroachment on quality decisions under two channel powers ie., the sequential quantity decision and simultaneous quantity decision showing that the manufacturer is more likely to encroach if they make simultaneous quantity decision However it is not known how quantity decision sequence affects the advertising decision and the manufacturer encroachment

Furthermore, coordination is useful to improve the profits of the supply chain further. Notice that the cost sharing mechanism is adopted in various situations to coordinate the supply chain. Bao et al. [4] explore how cost-sharing mechanism coordinate the supply chain in the vehicle market. Xie et al. [34] study the coordinating role of the buy-back contract under demand uncertainty. Many scholars also study the pricing and advertising decision in a single supply chain and investigate how to coordinate the supply chain $[19,20]$. In this paper, we also examine how to coordinate the supply by the cost-sharing mechanism. Since Bergen and John [5] define the vertical cooperative advertising as a financial agreement where the manufacturer bears a portion of his retailer's advertising cost, many studies on cooperative advertising explore whether the cooperative advertising can work and how it works when considering different factors. Considering a supply chain composed of a single manufacturer and a single retailer, Yang et al. [37] find that the fairness concern impacts the effectiveness of the cooperative advertising. Zhao et al. [43] develop a two-tier supply chain and see that whether the manufacturer can benefit from cooperative advertising depends on demand price elasticity. A two-player supply chain with the sticky price is constructed, discovering that cooperative advertising helps the channel members to escape from the prisoner's dilemma [23]. Studies mentioned above seldom study how the cooperative advertising works with manufacturer encroachment. Therefore, we will also investigate how cooperative advertising works under this circumstance.

To our best of knowledge, there are few studies taking advertising, manufacturer encroachment and quantity decision sequence into consideration. In our paper, models with dual distribution channels, including manufacturer's direct channel and retailer's traditional channel, are constructed to explore the advertising strategy, the effect of the manufacturer encroachment and the impact of the quantity decision sequence. To further improve the performance of the supply chain, we also study how to coordinate the supply chain. To be specific, we look into two ways of advertising cooperation and analyze the conditions under which they work. At last, an incentive cooperative advertising program different from the previous cooperative advertising program is investigated in this paper to achieve profit improvement.

\section{Model DeVElopment}

In this section, we consider a dual supply chain which comprises one manufacturer and one retailer. In our supply chain, the manufacturer produces a product at a fixed cost $c>0$. Then, he wholesales the product to the retailer and may sell the product directly online to consumers. Note that if the manufacturer decides to sell the product through a direct channel, he incurs an additional selling cost $s>0$ for each unit of product because of the lack of market experience [18], which represents his sell disadvantage. In addition, the manufacturer and the retailer inform customers by advertising before selling season and attract customers by the selling decisions at selling season.

Assuming that consumers decide whether to buy products or not according to the net utility they can obtain from a product and consumers have a diverse valuation of a product, the net utility of a product purchased by a consumer at price $p$ is $U=\theta v-p$, in which $\theta$ represents different consumer's various sensitivity to a product of value $v$. Following previous marketing literature $[11,26,40]$, we assume that consumers are heterogeneous in the valuation of the product. In other words, their perceived quality or their sensitivity to the quality of products are different. Consumer heterogeneity can be measured by the parameter $\theta$, which is supposed to be uniformly distributed on $[0,1]$. Consumers choose to purchase the product if $\theta v-p \geq 0$. Assuming the initial market size 
without advertising is $\alpha$. Therefore, the demand of the product concerning price is

$$
g(p)=\alpha\left(1-\frac{p}{v}\right) .
$$

Most authors, such as $[2,19,33]$, use a square root function to illustrate how the advertising expenditures can influence the customer demand, which suggests the diminishing marginal demand with the increase of advertising expenditures. Hence, we define the sales response function as

$$
h(A, a)=k_{m} \sqrt{A}+k_{r} \sqrt{a}
$$

where $k_{m}$ and $k_{r}$ are interpreted as advertising effectiveness of the manufacturer and the retailer, respectively. And the notation $A$ and $a$ are used to denominate the advertising expenditure of the manufacturer and the retailer, respectively. In line with previous literature $[2,33,39]$, the aggregate demand can be derived by the multiplication of the price demand and the sales response function. Here, the total demand is denoted as $q$. Thus, the total demand can be given as:

$$
q=g(p) h(A, a)=\alpha\left(1-\frac{p}{v}\right)\left(k_{m} \sqrt{A}+k_{r} \sqrt{a}\right) .
$$

Therefore, the inverse demand can be obtained as:

$$
p=v\left(1-\frac{q}{\alpha\left(k_{m} \sqrt{A}+k_{r} \sqrt{a}\right)}\right) .
$$

Inspired by Zhang et al. [40], we assume that the non-price campaign to improve the demand is launched before selling season. Thus, we assume that the advertising decision is prior to the wholesale decision and the quantity decision to inform and attract customers. Then, at the beginning of the selling season, the wholesale price and quantity are determined. Additionally, the advertising expenditure manufacturer inputs (i.e., national advertising promotion) usually precedes the advertising expenditure retailer inputs (i.e., store merchandising activities). The manufacturer makes advertising decision firstly in our case. Therefore, the decision-making are divided into three stages: advertising decision stage, wholesale decision stage and quantity decision stage.

Stage 1. The manufacturer decides his advertising expenditure $A$ at first and then the retailer determines his advertising expenditure $a$.

Stage 2. The manufacturer decides his wholesale price $w$.

Stage 3. The retailer chooses the order quantity $q_{r}$ and the manufacturer chooses the direct selling quantity $q_{m}$, respectively. In the quantity decision stage, we consider three different scenarios. To be specific, the manufacturer and the retailer make quantity decisions sequentially or they can make decisions simultaneously.

\subsection{Benchmark model}

We begin a basic model without encroachment where the manufacturer only wholesales the product to the retailer, which is denoted by a superscript "B". Note that the subscript " $\mathrm{r}$ " and " $\mathrm{m}$ " are used to denote the retailer and the manufacturer in this section and the following sections. The sequence of the events is similar to the above assumption, except that the manufacturer does not make quantity decision in the third stage. Thus, the total demand of the market is equal to the order quantity of the retailer, i.e., $q=q_{r}$. Then, the profits of the manufacturer and the retailer can be expressed as the following:

$$
\begin{aligned}
& \pi_{r}^{B}=(p-w) q_{r}-a \\
& \pi_{m}^{B}=(w-c) q_{r}-A .
\end{aligned}
$$

By substituting equation (3.4) into (3.5) and (3.6) and adopting backward induction, we can derive the optimal solutions as shown in Proposition 3.1 according the corresponding sequence. 
Proposition 3.1. When the manufacturer does not encroach, the optimal solutions can be given as:

$$
q_{r}^{B}=\frac{\alpha^{2}\left(2 k_{m}^{2}+k_{r}^{2}\right)(v-c)^{3}}{128 v^{2}}, \quad w^{B}=\frac{c+v}{2}, \quad A^{B}=\frac{k_{m}^{2}(v-c)^{4} \alpha^{2}}{256 v^{2}}, \quad a^{B}=\frac{k_{r}^{2}(v-c)^{4} \alpha^{2}}{1024 v^{2}} .
$$

Given the market demand $q$, the best response of the price can be obtained as $p^{B}=\frac{v+w}{2}$. It is interesting to note that the optimal price is linear with the wholesale price and has nothing to do with the advertising expenditure, which is consistent with the previous studies [33].

\subsection{Retailer-led quantity decision under encroachment}

In this subsection and the following subsection, we examine the scenarios where the manufacturer sells identical products to customers through his direct channels. Following the timeline of previous assumption, here we suppose that the retailer is the first-mover of quantity decision, which is denoted by a superscript "R". Thus, the profits of the manufacturer and the retailer are as follows:

$$
\begin{aligned}
& \pi_{m}^{R}=(p-c-s) q_{m}+(w-c) q_{r}-A \\
& \pi_{r}^{R}=(p-w) q_{r}-a .
\end{aligned}
$$

We can obtain the equilibrium decisions in this case as shown in Proposition 3.2.

Proposition 3.2. When the retailer makes order quantity decision firstly under encroachment, the equilibrium solutions can be given as the following:

$$
\begin{aligned}
\text { (i) } q_{m}^{R}=\frac{(-3 c-5 s+3 v)\left(8 s^{2} k_{r}^{2}+3 k_{m}^{2}\left(3 c^{2}+7 s^{2}+6 c(s-v)-6 s v+3 v^{2}\right)\right) \alpha^{2}}{432 v^{2}}, \\
q_{r}^{R}=\frac{s\left(8 s^{2} k_{r}^{2}+3 k_{m}^{2}\left(3 c^{2}+7 s^{2}+6 c(s-v)-6 s v+3 v^{2}\right)\right) \alpha^{2}}{108 v^{2}}, \\
\text { (ii) } w^{R}=\frac{3 v+3 c-s}{6}, \\
\text { (iii) } a^{R}=\frac{s^{4} k_{r}^{2} \alpha^{2}}{81 v^{2}}, A^{R}=\frac{k_{m}^{2}\left(3 c^{2}+7 s^{2}+6 c s-6(c+s) v+3 v^{2}\right)^{2} \alpha^{2}}{576 v^{2}} .
\end{aligned}
$$

According to the function of the inverse demand, the retail price in this case is $p^{R}=\frac{(3 c+s+3 v)}{6}$. In order to guarantee that the manufacturer encroachment makes sense, it is assumed that $q_{m}^{R}>0$, implying that $s<\frac{3}{5}(v-c)$. The result implies that the direct selling cost of the manufacturer should not be higher than $\frac{3}{5}(v-c)$, otherwise he would selling nothing in the direct channel.

\subsection{Manufacturer-led quantity decision under encroachment}

In this section, we examine the case that the manufacturer commits a direct selling quantity before the retailer's order quantity choices, which is denoted by superscript "M". Thus, the difference between the two cases is the quantity decision sequence in stage 3. In other words, the retailer has no first-mover advantage of quantity decision. According to backward induction, the optimal decisions of the manufacturer and the retailer can be obtained by using some algebraic techniques.

The following proposition gives the equilibrium solutions when the manufacturer commits the direct selling quantity firstly.

Proposition 3.3. When the manufacturer makes quantity decision When the manufacturer makes quantity decision before the retailer, the optimal solutions can be obtained as follows:

$\begin{aligned} \text { (i) } q_{m}^{M} & =\frac{(u-c-2 s)\left(s^{2} k_{r}^{2}+k_{m}^{2}\left(c^{2}+2 s^{2}+2 c(s-v)-2 s v+v^{2}\right)\right) \alpha^{2}}{16 v^{2}}, \\ & q_{r}^{M}=\frac{s\left(s^{2} k_{r}^{2}+k_{m}^{2}\left(c^{2}+2 s^{2}+2 c(s-v)-2 s v+v^{2}\right)\right) \alpha^{2}}{16 v^{2}}, \\ \text { (ii) } w^{M}=\frac{c+v}{2}, & \text { (iii) } a^{M}=\frac{s^{4} k_{r}^{2} \alpha^{2}}{64 v^{2}}, A^{M}=\frac{k_{m}^{2}\left(c^{2}+2 s^{2}+2 c s-2(c+s) v+v^{2}\right)^{2} \alpha^{2}}{64 v^{2}} .\end{aligned}$ 
Substituting the solutions into equation (3.4), the retail price in this case can be obtained as $p^{M}=\frac{v+c+s}{2}$. From the equilibrium of the manufacturer's quantity, we can draw that the manufacturer encroachment makes sense only when $s<\frac{v-c}{2}$. Obviously, the direct selling cost should be lower if the manufacturer can be a leader of the quantity decision stage, which implies that the manufacturer's direct selling cost disadvantage is less significant.

\subsection{Simultaneous quantity decision under encroachment}

In this section, we examine the case that the manufacturer commits a direct selling quantity before the retailer's order quantity decisions, which is denoted by superscript "M". To be specific, they make quantity decisions simultaneously. Based on this, we can conclude the following proposition to display the equilibrium solutions in this case.

Proposition 3.4. When the manufacturer and the retailer determine quantity decisions simultaneously, the optimal solutions can be given as follows:

(i) $q_{m}^{S}=\frac{(5 u-5 c-7 s)\left(16 s^{2} k_{r}^{2}+5 k_{m}^{2}\left(5 c^{2}+9 s^{2}+10 c(s-v)-10 s v+5 v^{2}\right)\right) \alpha^{2}}{2000 v^{2}}$, $q_{r}^{S}=\frac{s\left(16 s^{2} k_{r}^{2}+5 k_{m}^{2}\left(5 c^{2}+9 s^{2}+10 c(s-v)-10 s v+5 v^{2}\right)\right) \alpha^{2}}{500 v^{2}}$,

(ii) $w^{S}=\frac{5 c+5 v-s}{10}$,

(iii) $a^{S}=\frac{4 k_{r}^{2} s^{4} \alpha^{2}}{625 v^{4}}, A^{S}=\frac{k_{m}^{2}\left(5 c^{2}+9 s^{2}+10 c s-10(c+s) v+5 v^{2}\right)^{2} \alpha^{2}}{1600 v^{2}}$.

Similarly, we can have the equilibrium price as $p^{S}=\frac{5 v+5 c+3 s}{10}$. Note that $q_{m}^{S}>0$ implies that $s<\frac{5}{7}(v-c)$ such that the manufacturer encroachment makes sense. With the increase of his sell disadvantage $s$, he is likely to sell nothing through the online channel.

\subsection{Comparative analysis}

In this section, we investigate the effects of encroachment on the firms' decisions and profits. Based on the above results, we can come to the following conclusions when the retailer decides order quantity before the manufacturer.

Corollary 3.5. (i) When the retailer is the leader of the quantity decision stage, manufacturer encroachment decreases the retail price of the product and the wholesale price. Specifically, $p^{R}<p^{B}$ and $w^{R}<w^{B}$.

(ii) When the manufacturer encroaches under the retailer-led scenario, the retailer reduces his advertising expenditure, i.e., $a^{R}<a$, if $0<s<\frac{3}{4 \sqrt{2}}(v-c)$ and increases his advertising expenditure, i.e., $a^{R}>a^{B}$, if $\frac{3}{4 \sqrt{2}}(v-c)<s<\frac{3}{5}(v-c)$.

(iii) Different from the retailer, the manufacturer increases his advertising expenditure always in this case, i.e., $A^{R}>A^{B}$.

Corollary 3.5 states that customers can always benefit from the manufacturer's encroachment, for the retail price is always lower under encroachment. Intuitively, the encroachment aggravates the competition of channels and customers usually can benefit from seller's competition. As stated by Ha et al. [13], the manufacturer would stimulate the demand of retailer's channel by adjusting wholesale prices. It seems that the manufacturer is likely to charge a lower wholesale price when he encroaches. From Corollary 3.5, we can see that the retailer may increase or decrease the advertising expenditure based on the manufacturer's sell disadvantage $s$. The manufacturer's direct selling cost $s$ can represent his sales ability. To be specific, higher $s$ represents lower sales ability while lower $s$ represents higher sales ability. It seems that the retailer increases advertising investment when the manufacturer's sell disadvantage is significant. Otherwise, he decreases his advertising investment. Whereas, the manufacturer always invests more in advertising if he encroaches. Here, we denote ratio $1=\frac{q_{r}^{R}}{q_{m}^{R}+q_{r}^{R}}$ and ratio $2=\frac{q_{m}^{R}}{q_{m}^{R}+q_{r}^{R}}$ to represent the market share of the retailer and the manufacturer respectively in this 
case. Taking the derivative of ratio 1 and ratio 2 with respect to $s$, we can have the following conclusion which is in line with the previous study [13]. In a word, the manufacturer would like to divert a lot of demand to the retailer's channel with the increase of his sell disadvantage $s$. That can to some extent explain why the retailer is willing to invest more advertising expenditure if the direct selling cost is higher.

Corollary 3.6. Under the scenario of retailer-led quantity decision, the market share of the retailer's channel increases as the increase of the manufacturer's selling cost, i.e., $\frac{\partial \text { ratio } 1}{\partial s}>0$. On the contrary, the market share of the manufacturer's channel is decreasing as the increase of his selling cost $t$, i.e., $\frac{\partial \text { ratio } 2}{\partial s}<0$.

Corollary 3.6 demonstrates that the manufacturer's direct selling cost $s$ has a positive impact on the retailer's market share always but has a negative impact on the manufacturer's market share. The retailer tends to increase his advertising cost if the manufacturer's sell disadvantage increases such that he can earn more. The manufacturer gains profits from both the direct channel by himself and the traditional channel by retailer. Thus, the manufacturer needs to trade-off so that he would like to divert part of the demand to the retailer's channel if his efficiency is lower, i.e., $\frac{\partial \text { ratio } 1}{\partial s}>0$. Additionally, $s$ suggests that the efficiency of the direct channel is lower than that of the traditional channel. When making decisions, the manufacturer should make a balance between the benefits of market segmentation and the cost reduction for selling through a more efficient channel.

Corollary 3.7. (i) There exists a threshold $\widetilde{s_{1}}$. The retailer can benefit from the encroachment only when the manufacturer's direct selling cost is higher, i.e., $\pi_{r}^{R}>\pi_{r}^{B}$ when $\widetilde{s_{1}}<s<\frac{3}{5}(v-c)$.

(ii) If $k_{m}^{2}<\frac{1}{3} k_{r}^{2}$, there exists a threshold $\widetilde{s_{2}}$ and the manufacturer can benefit from encroachment only when the direct selling cost $s>\widetilde{s_{2}}$. If $k_{m}^{2}>\frac{1}{3} k_{r}^{2}$, the manufacturer may benefit from encroachment when his direct selling cost is relatively high or relatively low.

Corollary 3.7 indicates that the retailer can benefit from encroachment even when he does not increase his advertising expenditure sometimes, i.e., $\pi_{r}^{R}>\pi_{r}^{B}$ if $s$ in $\left[\widetilde{s_{1}}, \frac{3}{4 \sqrt{2}}(v-c)\right]$. It seems that the retailer get free ride from the manufacturer, where the retailer invests less advertising but earns more because of the increase of the manufacturer's advertising expenditure. As revealed by Corollary 3.6, higher direct selling cost is likely to make manufacturer to divert more products to the retailer's channel because the efficiency of the retailer's channel is more elevated. In that case, the retailer has some motivation to invest more in advertising with the increase of $s$. Though advertising results in cost, large $a$ improves market demand which increases the profits more significantly.

From the perspective of the manufacturer, the situation is more complicated, for he gets profits from both channels. Thus, the manufacturer should focus on the demand shift of both channels. When $k_{m}^{2}<\frac{1}{3} k_{r}^{2}$, the advertising effectiveness of the retailer is relatively high. Under this circumstance, lower direct selling cost $s$ prompts the retailer to cut down the expense of advertising. As a result, the negative impact on the manufacturer's profits due to that is more significant. So, he can not get more profit with encroachment if $s$ is lower. If the manufacturer's direct selling cost $s$ is high, the demand from both channels has grown because of higher investment of the retailer and the manufacturer, which makes advertising effectiveness advantage more significant. The higher advertising effectiveness advantage makes him earn more even when his direct selling cost is high. When $k_{m}^{2}>\frac{1}{3} k_{r}^{2}$, the advertising effectiveness of the manufacturer is relatively high. At this time, the manufacturer is more likely to encroach. To be specific, he may earn more when the direct selling cost is relatively low or relatively high. When the direct selling cost is high, the reason that the manufacturer obtains higher profits is similar to what we explain before. When the direct selling cost low, more demand shifts to the manufacturer's channel. If $k_{m}^{2}>\frac{1}{3} k_{r}^{2}$, the negative impact due to the retailer's cutting on advertising is weaker. In this case, the positive effect of the demand shift dominates the negative effect of the retailer's cutting on advertising. Thus, the manufacturer can benefit from encroachment though the retailer invests less in advertising when $s$ is low.

Corollary 3.7 implies that the manufacturer is more likely to encroach if his advertising effectiveness is higher. In a word, the manufacturer is supposed to enhance his advertising effectiveness $k_{m}$ to avoid the negative effect 
of the decrease of the retailer's advertising expenditure. Additionally, he is more likely to earn more whatever his direct selling cost is. Thus, the manufacturer should make an effort to improve his advertising effectiveness.

Corollary 3.8. If the manufacturer commits the direct selling quantity firstly, the retail price is always lower while the wholesale price is the same, i.e., $p^{M}<p^{B}$ and $w^{M}=w^{B}$. Additionally, the advertising expenditure by the manufacturer is always higher while the retailer's advertising expenditure is always lower in this case, i.e., $A^{M}>A^{B}$ and $a^{M}<a^{B}$.

Similarly, the channel competition in this case also reduces the retail price. However, the manufacturer will not adjust the wholesale price if the retailer has no first-mover advantage of the quantity decision. Note that the retailer always reduces his advertising investment in the manufacturer-led case whatever the direct selling cost is. Whereas, the manufacturer always invests more in advertising. Under the manufacturer-led scenario, the negative impact of the encroachment on the retailer's profit is so strong and the gain by advertising is not enough to offset the loss. In this case, the retailer's quantity decision does not pose a marked impact on the manufacturer's quantity. Consequently, more demand shifts from the retailer's channel to the manufacturer's channel under the manufacturer-led scenario. Additionally, the manufacturer benefits more from encroachment so that he would like to spend more. However, the retailer seems to lose from encroachment always so that he is reluctant to invest more.

Corollary 3.9. (i) When the manufacturer decides the quantity decision firstly, the retailer always loses whatever the direct selling cost is, i.e., $\pi_{r}^{M}<\pi_{r}^{B}$.

(ii) When $k_{m}^{2}>\frac{1}{3} k_{r}^{2}$, there exists a threshold $\widetilde{s_{2}}$ and the manufacturer can get higher profit with encroachment if $s>\widetilde{s_{3}}$; When $k_{m}^{2}<\frac{1}{3} k_{r}^{2}$, he loses always with encroachment.

As illustrated by Corollary 3.9, the retailer loses always when manufacturer encroachment happens in this case, which is different from the retailer-led scenario. It is intuitive that under manufacturer-led scenario the effect of manufacturer encroachment is so strong that the retailer can not benefit from it. In this situation, the manufacturer charges the same wholesale price while the retail price goes down so that retailer's profit of each unit product is lower. Moreover, the manufacturer dominates the quantity decision over the retailer. Corollary 3.9 states that the manufacturer-led quantity decision makes the channel competition more intense. If the manufacturer commits direct selling quantity firstly, it may lead to a lose-lose result. It seems that firms have no incentive to do so.

Comparing the benchmark and the simultaneous quantity decision with encroachment, we obtain the following propositions.

Corollary 3.10. (i) When firms make quantity decision simultaneously, both the retail price and the wholesale price are lower, i.e., $p^{S}<p^{B}$ and $w^{S}<w^{B}$.

(ii) When firms make quantity decisions simultaneously, the retailer increases his advertising expenditure if and only if $s>\frac{5}{8}(v-c)$.

(iii) When firms make quantity decisions simultaneously, the manufacturer increases his advertising expenditure if and only if $s<\frac{10-\sqrt{10}}{18}(v-c)$.

Corollary 3.11. (i) When firms make quantity decisions simultaneously with encroachment, there exists a threshold $\widetilde{s_{4}}$ such that the retailer loses always if $s<\widetilde{s_{4}}$.

(ii) When firms make quantity decision simultaneously with encroachment, whether the manufacturer can benefit from encroachment depends on the direct selling cost and the relative advertising effectiveness. If $k_{m}^{2}<$ $\frac{1}{3} k_{r}^{2}$, he can benefit from encroachment if $s>\widetilde{s_{5}}$. If $k_{m}^{2}>\frac{671}{97} k_{r}^{2}$, he can benefit from encroachment if $s<\widetilde{s_{6}}$. If $\frac{1}{3} k_{r}^{2}<k_{m}^{2}<\frac{671}{97} k_{r}^{2}$, he may benefit from encroachment when the direct selling cost is relatively high or relatively low. 
Corollary 3.10 also states that manufacturer encroachment reduces the retail price and the wholesale price. There exists a threshold such that the retailer increases his advertising investment when the manufacturer's direct selling cost is higher than the threshold. It is similar to the scenario of the retailer-led quantity decision, except that the threshold of the former is higher than that of the latter. It is reasonable that the retailer has the first-mover advantage such that he can get higher even when $s$ is relatively low.

As demonstrated by Corollary 3.11, the encroachment may hurt the retailer when the manufacturer's sell disadvantage is small. Additionally, the manufacturer is likely to lose with encroachment when his direct selling cost is intermediate. Specifically, he can get higher profits with encroachment when the direct selling cost is relatively low or relatively high.

As revealed by some studies $[13,39]$, the change of quantity decision have an impact on the players' optimal choices. In this subsection, we make some comparisons under three cases with encroachment. Based on the equilibrium solutions, we can obtain the following propositions.

Corollary 3.12. Under three cases with encroachment, the relationship of the advertising strategy between them can be given as:

(i) $a^{M}>a^{R}>a^{S}$,

(ii) $A^{R}>A^{M}>A^{S}$.

It can be seen that firms tend to invest more in advertising if they do not have the first-mover advantage of quantity decision. The retailer spends the most on advertising if the manufacturer determines the direct selling quantity firstly. Whereas, the manufacturer spends the most on advertising if the retailer orders selling quantity before the manufacturer. It seems that the firm in weak position tends to make greater efforts so as to compete with the other.

\section{Advertising COOPERAtion}

In this section, we consider two kinds of advertising cooperation, i.e., the cooperative advertising and the centralized advertising decision-making. The cooperative advertising program indicates that in stage 1 the manufacturer and the retailer make advertising decisions independently while the manufacturer reimburses part of the retailer's advertising expenditure. Note that the portion undertaken by the manufacturer is denoted as " $\beta$ ". The centralized advertising decision-making means that in stage 1 the manufacturer and the retailer make advertising decisions together. Additionally, in this section we mainly focus on the retailer-led quantity decision scenario to explore advertising cooperation, which is more common and in line with previous studies [13,39]. As stated by Ha et al. [13], the manufacturer encroachment leads to channel competition so that the manufacturer is supposed do something to coordinate it, i.e., orders are first filled at the nearest retail store.

\subsection{Cooperative advertising program}

Previous studies on cooperative advertising show that the cooperative advertising program encourages the retailer to invest more in advertising, leading to the improvement of the supply chain $[23,33]$. In this section, we consider a supply chain where the manufacturer undertakes a part of the retailer's advertising expenditures, which is denoted by superscript "DA". The sequence of the event is the same as the above. The only difference is that in stage 1 the manufacturer decides the advertising expenditure $A$ and the subsidy rate $\beta$. The profits of the manufacturer and the retailer can be given as:

$$
\begin{aligned}
& \pi_{r}^{\mathrm{DA}}=(p-w) q_{r}-(1-\beta) a \\
& \pi_{m}^{\mathrm{DA}}=(p-c-s) q_{m}+(w-c) q_{r}-A-\beta a .
\end{aligned}
$$

Backward induction is used to solve the problem. Thus, the following proposition and corollary can be obtained. 
TABLE 1. Equilibrium solutions when the cooperative advertising program is adopted.

\begin{tabular}{ll}
\hline \hline Wholesale price, $w^{\mathrm{DA}}$ & $\frac{3 v+3 c-s}{6}$ \\
Manufacturer's subsidy rate, $\beta^{\mathrm{DA}}$ & $\frac{9 c^{2}+18 c s+17 s^{2}-18 c v-18 s v+9 v^{2}}{9 c^{2}+18 c s+25 s^{2}-18 c v-18 s v+9 v^{2}}$ \\
Retailer's advertising expenditure, $a^{\mathrm{DA}}$ & $\frac{k_{r}^{2} s^{4} \alpha^{2}}{81 v^{2}\left(1-\beta^{\mathrm{DA}}\right)^{2}}$ \\
Manufacturer's advertising expenditure, $A^{\mathrm{DA}}$ & $\frac{k_{m}^{2}\left(3 c^{2}+6 c s+7 s^{2}-6 c v-6 s v+3 v^{2}\right)^{2} \alpha^{2}}{576 v^{2}}$ \\
Retail price, $p^{\mathrm{DA}}$ & $\frac{3 v+3 c+s}{6}$ \\
Retailer's order quantity, $q_{r}^{\mathrm{DA}}$ & $\frac{\left(k_{m} \sqrt{A^{\mathrm{DA}}}+k_{r} \sqrt{a^{\mathrm{DA}}}\right) 2 s \alpha}{3 v}$ \\
Manufacturer's selling quantity, $q_{m}^{\mathrm{DA}}$ & $\frac{\left(k_{m} \sqrt{A^{\mathrm{DA}}}+k_{r} \sqrt{a^{\mathrm{DA}}}\right)(3 v-3 c-5 s) \alpha}{6 v}$ \\
\hline
\end{tabular}

Proposition 4.1. When the cooperative advertising program is selected, the optimal solutions are shown in Table 1.

Corollary 4.2. The cooperative advertising program can improve the performance of the supply chain, i.e., $\pi_{r}^{\mathrm{DA}}>\pi_{r}^{R}$ and $\pi_{m}^{\mathrm{DA}}>\pi_{m}^{R}$.

Proposition 4.1 shows that the retailer's advertising expenditures increase with the subsidy rate of the manufacturer. Thus, the market demand $q_{r}^{\mathrm{DA}}$ and $q_{m}^{\mathrm{DA}}$ increase as well such that the profits of the manufacturer and the retailer increase. As illustrated by Corollary 4.2, the cooperative advertising program is useful to improve the performance of the supply chain.

\subsection{Centralized advertising decision-making}

As revealed by the previous literature, the centralized decision-making generally performs better than the decentralized decision-making. In this section, we consider another way of advertising cooperation. We assume that in stage 1 the manufacturer and the retailer make advertising decision together, which is denoted by superscript "CA". Solving backward, we can obtain the optimal quantity and wholesale price as previous section. The only difference is that in stage 1 the advertising expenditures of the retailer and the manufacturer are determined by maximizing the profit of the supply chain:

$$
\pi_{s}^{\mathrm{CA}}=(p-c-s) q_{m}+(p-c) q_{r}-A-a .
$$

By solving $\frac{\partial \pi_{s}^{\mathrm{CA}}}{\partial A}=0$ and $\frac{\partial \pi_{s}^{\mathrm{CA}}}{\partial a}=0$, we can generate the optimal advertising expenditure $A^{\mathrm{CA}}$ and $a^{\mathrm{CA}}$. The second-sorder condition is satisfied as well. Therefore, the following conclusions can be obtained.

Proposition 4.3. Under the centralized advertising decision-making, the optimal solutions are shown in Table 2.

Both the cooperative advertising program and the centralized advertising decision-making are ways of advertising cooperation. Note that under the centralized advertising decision-making, firms invest more in advertising, i.e., $A^{\mathrm{CA}}>A^{\mathrm{DA}}$ and $a^{\mathrm{CA}}>a^{\mathrm{DA}}$, such that the market demand will increase. However, it does not imply that the profits of the retailer and the manufacturer will increase as well. In fact, which way of cooperation is better depends on the relative relationship of $k_{m}$ and $k_{r}$. Consistent with the previous study [23,33], here we denote the relative relationship between $k_{m}$ and $k_{r}$ as $\delta=\frac{k_{m}}{k_{r}}$. Higher $\delta$ indicates that the manufacturer's advertising effectiveness is much more significant than the retailer's. Whereas, lower $\delta$ suggests that the retailer's advertising effectiveness is much more significant. 
TABLE 2. Equilibrium solutions when the advertising decision-making is centralized.

\begin{tabular}{ll}
\hline \hline Wholesale price, $w^{\mathrm{CA}}$ & $\frac{3 v+3 c-s}{6}$ \\
Retailer's advertising expenditure, $a^{\mathrm{CA}}$ & $\frac{k_{r}^{2}\left(9 c^{2}+18 c s+29 s^{2}-18 c v-18 s v+9 v^{2}\right)^{2} \alpha^{2}}{5184 v^{2}}$ \\
Manufacturer's advertising expenditure, $A^{\mathrm{CA}}$ & $\frac{k_{m}^{2}\left(9 c^{2}+18 c s+29 s^{2}-18 c v-18 s v+9 v^{2}\right)^{2} \alpha^{2}}{5184 v^{2}}$ \\
Retail price, $p^{\mathrm{CA}}$ & $\frac{3 v+3 c+s}{6}$ \\
Retailer's quantity, $q_{r}^{\mathrm{CA}}$ & $\frac{\left(k_{m} \sqrt{A^{\mathrm{CA}}}+k_{r} \sqrt{a^{\mathrm{CA}}}\right) 2 s \alpha}{3 v}$ \\
Manufacturer's quantity, $q_{m}^{\mathrm{CA}}$ & $\frac{\left(k_{m} \sqrt{A^{\mathrm{CA}}}+k_{r} \sqrt{a^{\mathrm{CA}}}\right)(3 v-3 c-5 s) \alpha}{6 v}$ \\
\hline
\end{tabular}

Corollary 4.4. (i) From the perspective of the supply chain, the centralized advertising decision-making is always a better way of advertising cooperation, which results in higher profits for the supply chain, i.e., $\pi_{s}^{\mathrm{CA}}>$ $\pi_{s}^{\mathrm{DA}}$.

(ii) For the retailer, he can get higher profit from the centralized advertising decision-making when $\delta>\widetilde{\delta_{1}}$. Otherwise, he gets higher profit from the cooperative advertising program.

(iii) For the manufacturer, he can get higher profit from the centralized advertising decision-making when $\delta<\widetilde{\delta_{2}}$. Otherwise, he get higher profit from the cooperative advertising program.

Corollary 4.4 shows that the centralized advertising decision-making is a better way of advertising cooperation for the supply chain. However, it is hard to achieve in reality. In fact, firms tend to make advertising decision by themselves. Moreover, the centralized advertising decision-making can be adopted only when both firms can get higher profits from it than from the cooperative advertising program. As illustrated by Corollary 4.4, it can be seen that both firms can get higher profits only within a certain range $\left[\widetilde{\delta}_{1}, \widetilde{\delta}_{2}\right]$. When $\delta<\widetilde{\delta_{1}}$, the retailer is better off to choose the cooperative advertising program. When $\delta>\widetilde{\delta_{2}}$, the manufacturer is better off to choose the cooperative advertising program.

\subsection{Incentive cooperative advertising program}

As mentioned in the previous section, the centralized advertising decision-making allows the supply chain to perform better and the cooperative advertising program can improve the profits of each member to some degree. However, there is still room for improvement in terms of the cooperative advertising program. These results provoke a doubt: Do there exist any other mechanism to allow channel members to take action independently and obtain higher profits at the same time? It is necessary to design a contract so that all players can make better choices even when they make decisions independently.

In this subsection, we extend the cooperative advertising program afore to a new program that we call incentive cooperative advertising program denoted by superscript "IA" to improve the players' profits further. Inspired by block pricing strategy [16,41], in this paper we propose a block subsidy strategy. The manufacturer adopts two kinds of subsidy rates, i.e., the basic and the higher. If the retailer's advertising expenditure is lower than a threshold, the manufacturer takes the basic subsidy rate. If the retailer's advertising expenditure is higher than the threshold, the manufacturer adopts the higher subsidy rate. Observing the threshold of the advertising expenditure and the subsidy rate of two parts set by the manufacturer, the retailer decides his advertising expenditure. Base on the cooperative advertising program, we might as well set the basic subsidy rate as $\beta_{b}$ that is the optimal choice for the manufacturer under the cooperative advertising program, i.e., $\beta_{b}=\frac{9 c^{2}+18 c s+17 s^{2}-18 c v-18 s v+9 v^{2}}{9 c^{2}+18 c s+25 s^{2}-18 c v-18 s v+9 v^{2}}$. In addition, a threshold of retailer's advertising expenditure $a_{b}$ which is the optimal advertising expenditure of the retailer when the subsidy rate is $\beta_{b}$ under the cooperative advertising program. Given the threshold and the basic subsidy rate, the manufacturer only determines the higher subsidy 
rate, which is defined as $\varphi$. The sequence of the incentive cooperative advertising program is similar to that of the cooperative advertising program. The only difference is that in stage 1 the manufacturer decides the higher subsidy rate $\varphi$ and his advertising expenditure $A$. Similarly, in stage 1 the retailer determines his advertising expenditure when the manufacturer announces his decisions. In stage 2 , the wholesale price is determined. In stage 3 , the selling quantities of the manufacturer and the retailer are determined.

In this subsection, we define the profits of the retailer and the manufacturer as $\pi_{r}^{\mathrm{IA}}$ and $\pi_{m}^{\mathrm{IA}}$, respectively, when adopting the incentive cooperative advertising program. Similar to Section 4.1, the order quantity, the direct selling quantity and the wholesale price can be solved successively by using backward induction. Thus, in stage 1 the retailer decides his advertising expenditure to maximize his profit

$$
\pi_{r}^{\mathrm{IA}}(a)=\left\{\begin{array}{ll}
(p-w) q_{r}-\left(1-\beta_{b}\right) a & \text { if } a \leq a_{b} \\
(p-w) q_{r}-\left(1-\beta_{b}\right) a-\left(a-a_{b}\right)(1-\varphi) & \text { if } a>a_{b}
\end{array} .\right.
$$

Anticipating this, the manufacturer chooses the higher subsidy rate $\varphi$ and advertising expenditure $A$ to maximize his profit

$$
\pi_{m}^{\mathrm{IA}}(A, \varphi)=\left\{\begin{array}{ll}
(p-c-s) q_{m}+(w-c) q_{r}-A-\beta_{b} a & \text { if } a \leq a_{b} \\
(p-c-s) q_{m}+(w-c) q_{r}-A-\beta_{b} a_{b}-\left(a-a_{b}\right) \varphi & \text { if } a>a_{b}
\end{array} .\right.
$$

We provide the following proposition to confirm that the incentive cooperative advertising program takes effect. The proof can be seen in Appendix A.

Proposition 4.5. When the incentive cooperative advertising program is adopted, both firms can get a higher profit, i.e., $\pi_{r}^{\mathrm{IA}} \geq \pi_{r}^{\mathrm{DA}}$ and $\pi_{m}^{\mathrm{IA}} \geq \pi_{m}^{\mathrm{DA}}$ at the equilibrium points.

Proposition 4.5 indicates that the incentive cooperative advertising program can improve the profits of both firms. Such an incentive cooperative advertising program induces the retailer to input more local advertising and helps the manufacturer to increase his profit as well. As revealed by the previous section, a higher subsidy rate prompts the retailer to make a greater effort in advertising, which can enlarge the demand to some degree. However, a higher subsidy rate makes it costly for the manufacturer to boost sales. Obviously, the manufacturer expects the retailer to invest more while he shares less. Paradoxically, the retailer is reluctant to invest more if the manufacturer shares less. The incentive cooperative advertising program defuses the conflict. The manufacturer provides higher subsidy rate so that the retailer is willing to invest more. Note that the manufacturer does not use a high subsidy rate for all advertising expenditures always, which reduces the burden on the manufacturer. Therefore, win-win results arise.

\section{ILlustrative InStANCE}

In this section, numerical examples are provided to illustrate the results of this paper more intuitively. As discussed before, the direct selling cost and the advertising effectiveness have an impact on the effects of the manufacturer encroachment. Figure 1 shows the advertising expenditures and profits of the manufacturer and the retailer under different cases. Note that the black line, purple lines, blue lines and red lines denote the benchmark case, the retailer-led case, the manufacturer-led case and the simultaneous case, respectively. As shown in Figure 1a, the retailer decreases his advertising expenditure always under the manufacturer-led quantity decisions. If $s>0.424$, he increases his advertising expenditure when the manufacturer encroaches under the scenario of the retailer-led quantity decision. When they make quantity decisions simultaneously, the retailer increases advertising expenditure only when $s>0.500$. Additionally, it can be seen from Figure $1 \mathrm{~b}$ that the manufacturer increases advertising expenditure always in two cases, i.e., the manufacturer-led quantity decision and the retailer-led quantity decision. In the simultaneous case, he increases advertising expenditure only when $s<0.304$. Obviously, the firms increase advertising expenditure when the situation is conducive to them. 


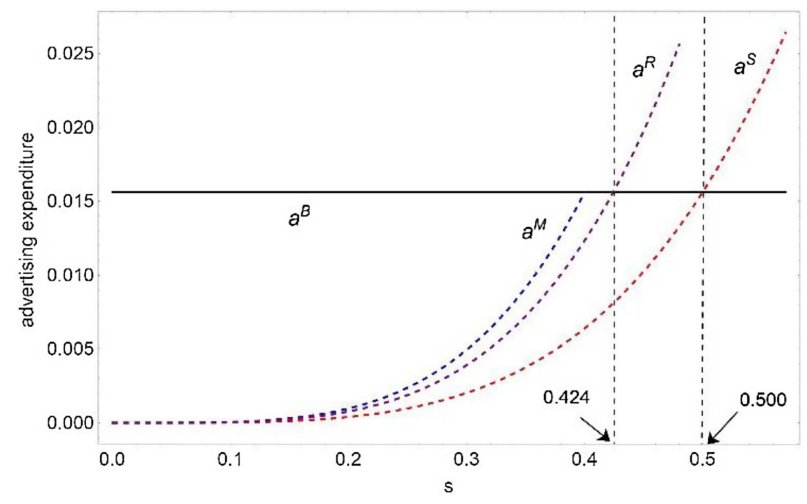

(a)

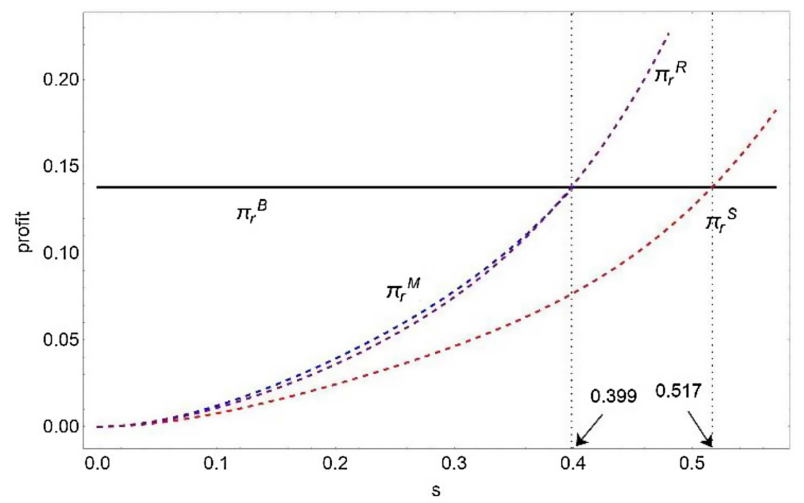

(c)

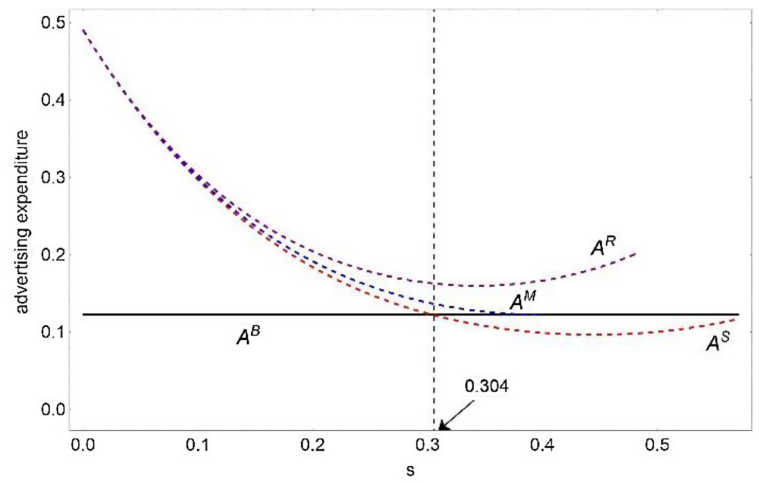

(b)

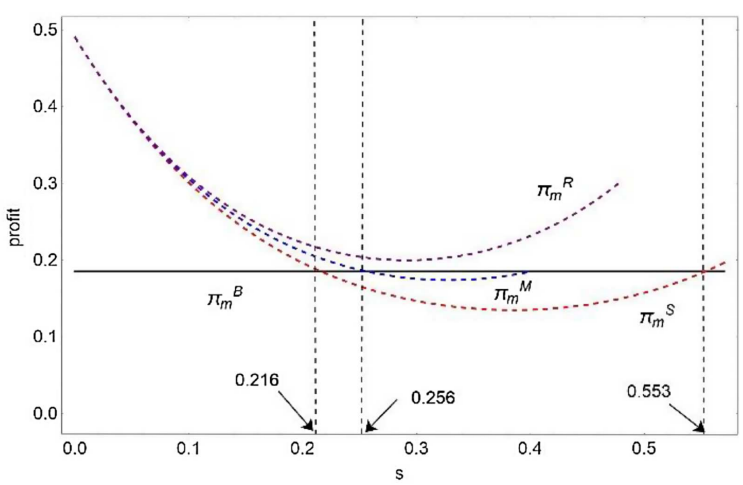

(d)

FiguRE 1. Advertising expenditure and profits with different $s$ under different cases. (a) Retailer's advertising. (b) Manufacturer's advertising. (c) Retailer's profit. (d) Manufacturer's profit.

Since it is challenging to derive the analytical results directly, we examine the effects of quantity decision sequence on profits by carrying out a numerical study. Figures $1 \mathrm{c}$ and $1 \mathrm{~d}$ demonstrate the effects of encroachment on firms' profit. If the manufacturer makes quantity decision first, the retailer is worse off with encroachment always. Whereas, in the other two cases, he can get higher profits when $s$ is higher, i.e., $s>0.399$ and $s>0.517$. Figure 1d illustrates that situations when $k_{m}^{2}>\frac{1}{3} k_{r}^{2}$. It can be seen that the manufacturer is likely to benefit from encroachment always in the retailer-led case. If he commits the direct selling quantity firstly, he can get higher profits only when his sell disadvantage is small, i.e., $s<0.256$. In line with Proposition 4.3, he benefits from encroachment in the simultaneous case when $s$ is relatively low or relatively high, i.e., $s<0.216$ and $s>0.553$, while he loses with encroachment when $s$ is intermediate. Moreover, it can be seen that the manufacturer can get the highest profit under the scenario of the retailer-led case among the three cases, which is consistent with Zhang et al. [39] who claim that the manufacturer has no incentive to commit the direct selling quantity firstly.

Figure 2 depicts how advertising effectiveness influences the effects of manufacturer encroachment on his profits under different cases. In the blue region of Figure 2a, the minimum profits of the manufacturer with respect to $s$ is greater than zero. Thus, it indicates that, under the scenario of the retailer-led quantity decision, the manufacturer is likely to benefit from encroachment always as long as his advertising effectiveness is 


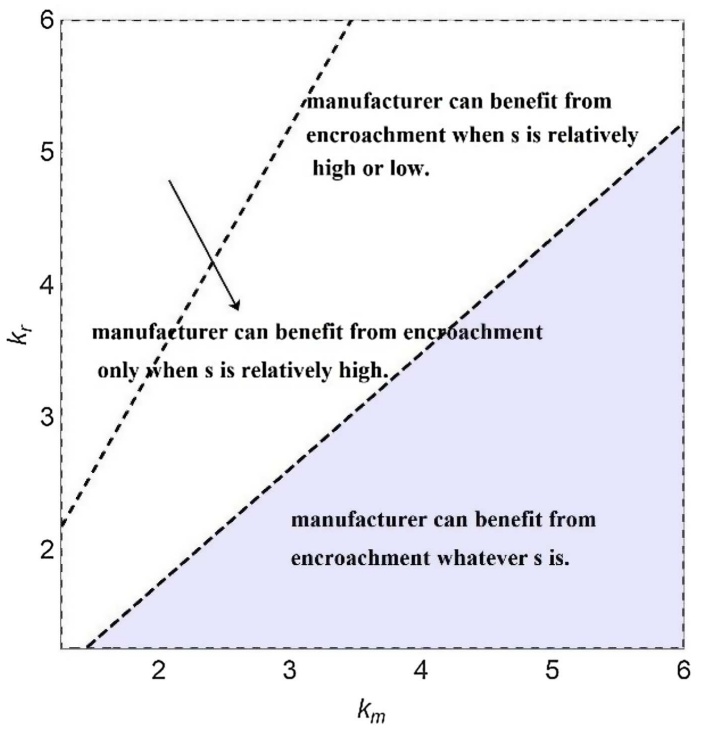

(a)

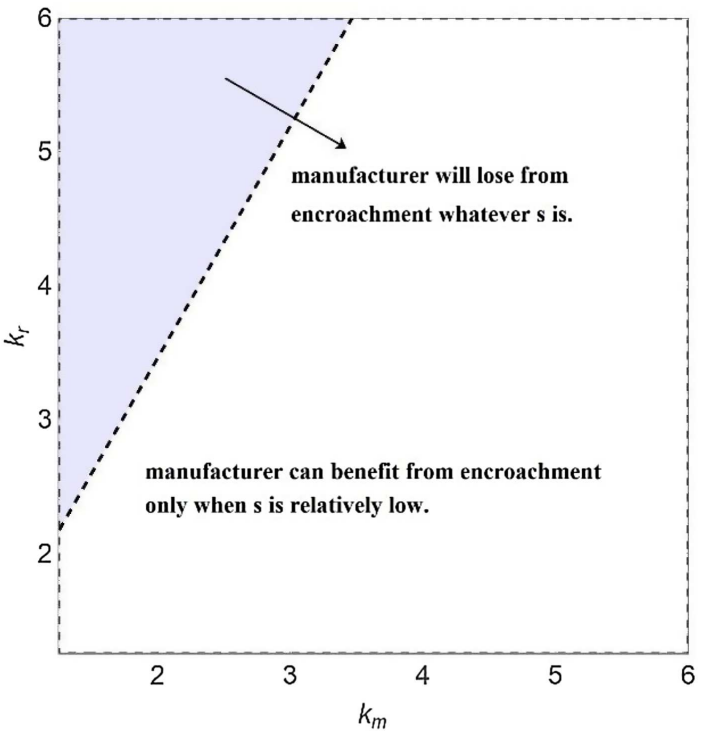

(b)

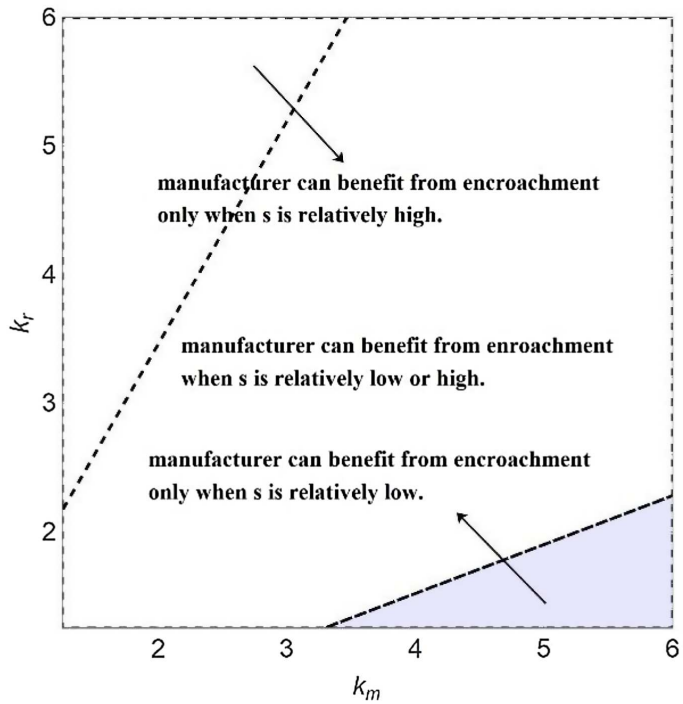

(c)

Figure 2. The effects of manufacturer encroachment on manufacturer via advertising effectiveness. (a) Retailer-led case (b) Manufacturer-led case. (c) Simultaneous case.

relatively high. Additionally, if his advertising effectiveness is relatively low, he can get more with encroachment only when $s$ is high. In this case, the retailer's advertising effectiveness is relatively high and he increases advertising expenditure, which results in demand increase of both channels. From Figure 2b, we can know that the manufacturer-led case is likely to result in lose-lose situations if the manufacturer's advertising effectiveness is relatively low. At this time, the negative impact of the retailer's reduction of advertising effort has been significant, resulting in the profits fall. Figure 2c illustrates the case of simultaneous quantity decision. If 


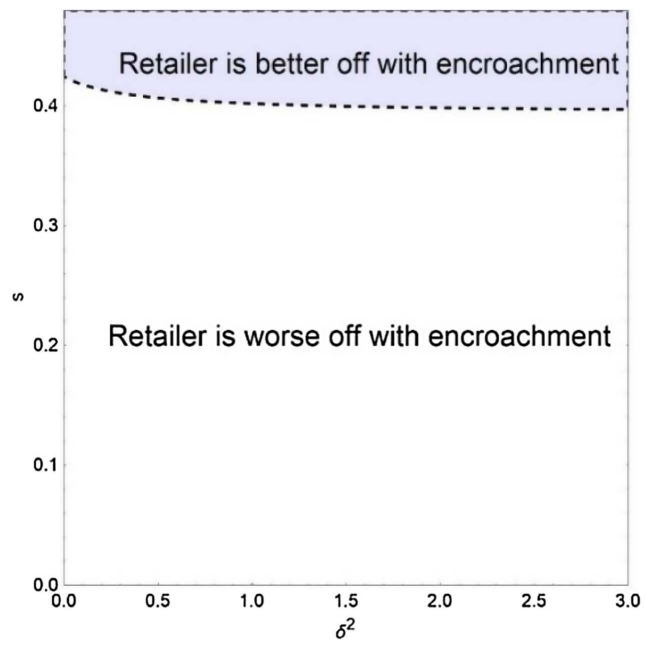

(a)

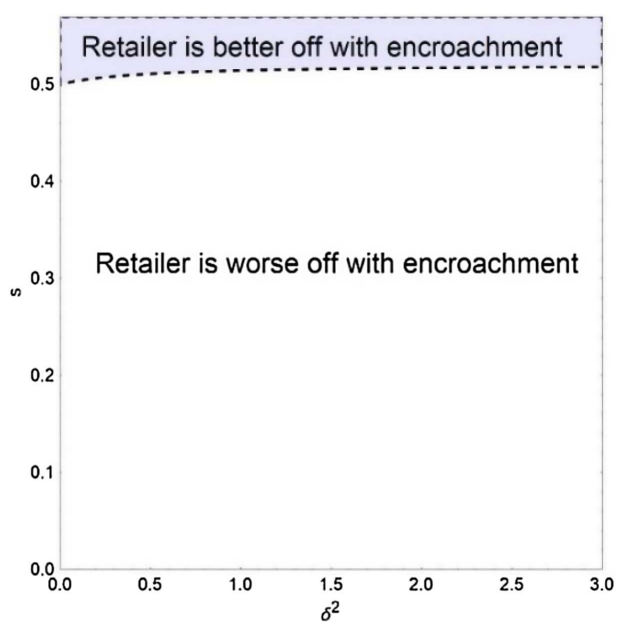

(b)

FigURE 3. The effects of manufacturer encroachment on retailer via different parameters. (a) Retailer-led case. (b) Simultaneous case.

$\delta=\frac{k_{m}}{k_{r}}$ is intermediate, the manufacturer can benefit from encroachment when his advertising effectiveness is relatively high or low. If $\delta$ is relatively high, namely the manufacturer's advertising effectiveness is higher, small sell disadvantage $s$ allows him to obtain more with encroachment. If $\delta$ is relatively low, namely the retailer's advertising effectiveness is higher, enormous sell advantage $s$ makes him get more with encroachment because the retailer invest more in advertising to boost sales.

Figure 3 indicates the impact of encroachment on retailer's profit regarding to $s$ and $\delta^{2}$. $\delta^{2}$ represents the relative advertising effectiveness between the manufacturer and the retailer. For any given advertising effectiveness, it can be seen that the retailer is better off with encroachment only when the manufacturer's sell disadvantage $s$ is higher, which is consistent with Figure 1c and previous corollaries. Moreover, Figure 3 shows that the threshold of $s$ decreases with the increase of $\delta^{2}$ in retailer-led case. Besides, it depicts that $s$ increases with the rise of $\delta^{2}$ in the simultaneous case.

Figure 4 illustrates the impact of advertising effectiveness on firms' advertising cooperation. As shown by Figures $4 \mathrm{a}$ and $4 \mathrm{~b}$, the retailer (manufacturer) get higher profits from the cooperative advertising program rather than the centralized advertising decision-making when the retailer's (manufacturer's) advertising effectiveness is higher. It is intuitive that one is more likely to decide from the perspective of his profit if he can perform better, i.e., his advertising effectiveness is relatively high. As displayed by Figure 4c, firms get higher profits from centralized advertising decision-making in the blue region. Obviously, firms making decisions on their own with cooperative adverting program is better off under most circumstances. What's more, firms tend to make decisions independently.

From previous section, we can know that the incentive cooperative advertising program can bring higher profits to enterprises. Here, the numerical examples are used to show intuitively the effectiveness of the incentive cooperative advertising program. Note that the red lines and the black lines represent the profits under the cooperative advertising program and the incentive cooperative advertising program, respectively. Figure 5 shows how firm's profits vary with $\varphi$. Since $\varphi$ is the incentive subsidy rate, it no doubt should be higher than $\beta_{b}$. First, we can see that for any $\varphi>\beta_{b}=0.805, \pi_{r}^{\mathrm{IA}}>\pi_{r}^{\mathrm{DA}}$ holds. Second, we can find that the manufacturer gains the highest profit at the optimal $\varphi=0.833$ and the corresponding profit $\pi_{m}^{\mathrm{IA}}>\pi_{m}^{\mathrm{DA}}$. Consequently, the incentive 


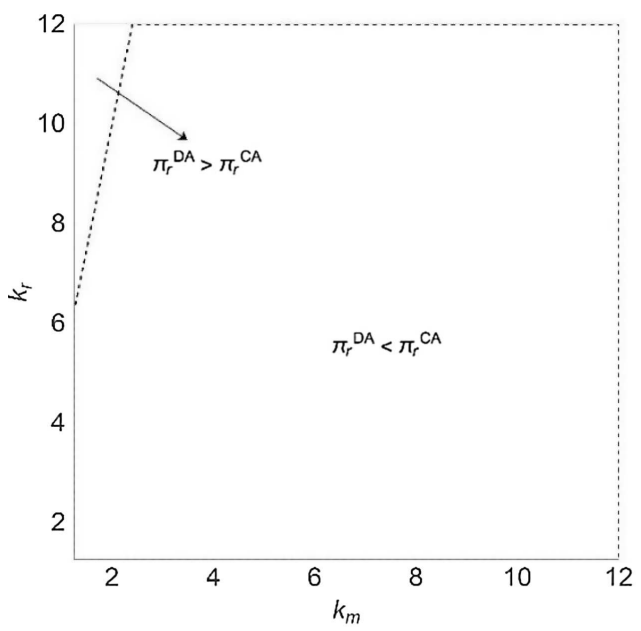

(a)

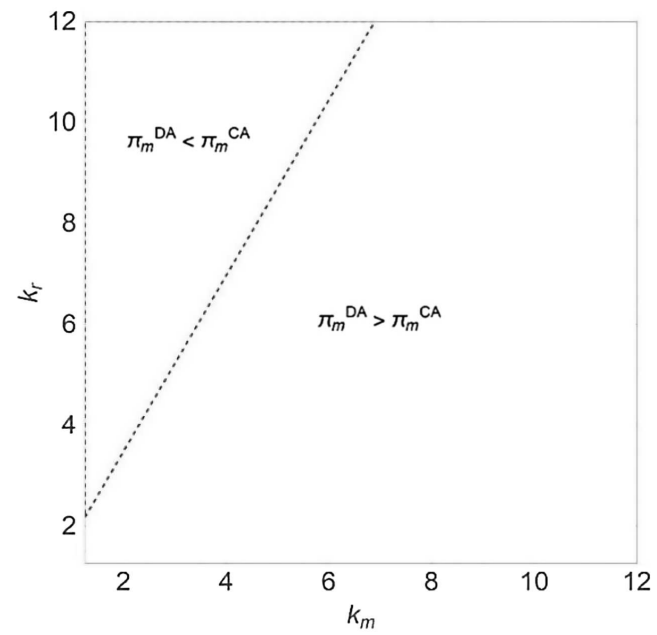

(b)

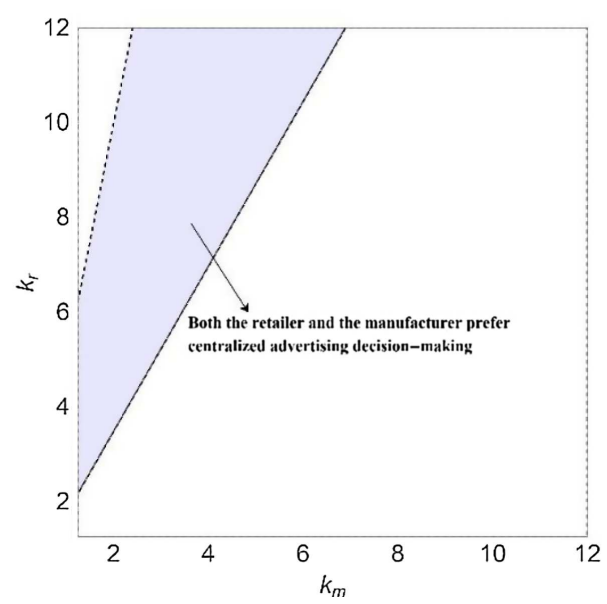

(c)

FiguRE 4. The effects of the advertising effectiveness on advertising cooperation. (a) Retailer's profit with $k_{m}$ and $k_{r}$. (b) Manufacturer's profit with $k_{m}$ and $k_{r}$. (c) Effects of cooperation.

cooperative adverting program can further improve the performance of the supply chain and make firms obtain higher profit.

\section{Conclusion}

In practice, manufacturer encroachment is universal due to the rapid development of e-commerce. Manufacturers and retailers are willing to advertise to promote sales. Moreover, manufacturers often use cooperative advertising to influence retailers' advertising decisions. Our research branches out one-manufacturer one-retailer co-op advertising models with one distribution channel into a supply chain with dual distribution channels. In this case, manufacturers can sell products through both physical channels operated by retailers and online channels by themselves. First, we examine how manufacturer encroachment affects the advertising strategies and profits of the firms under three different cases. Second, we take the cooperative advertising program into 


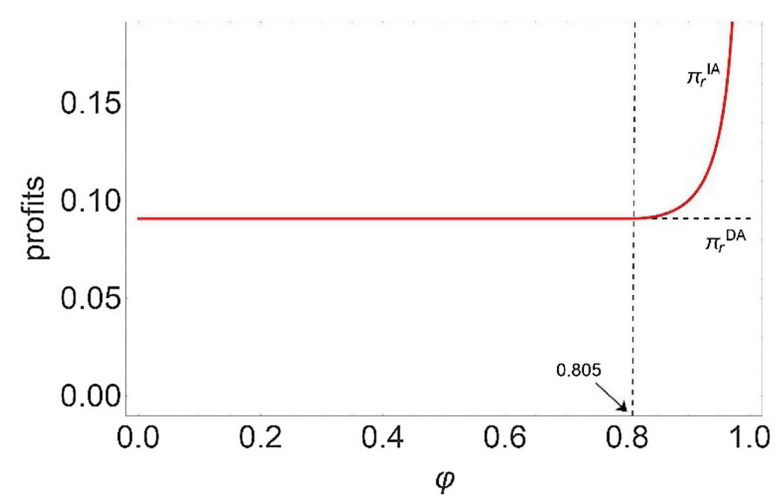

(a)

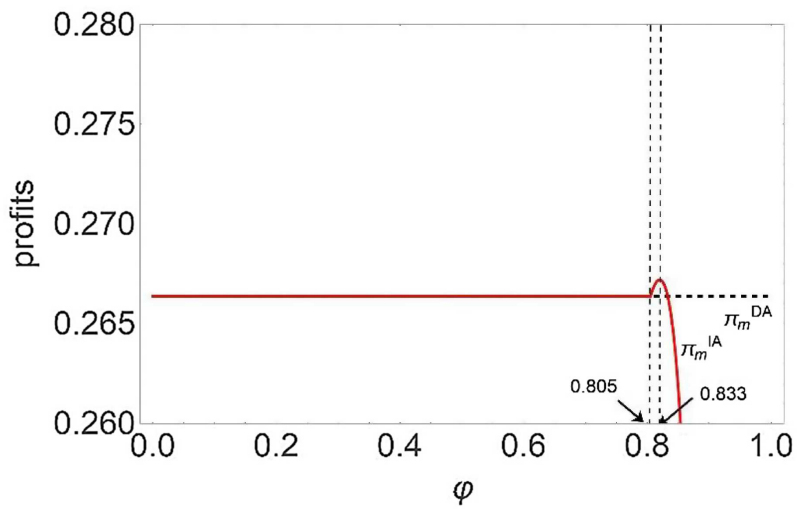

(b)

Figure 5. Profits with $\varphi$ under the incentive cooperative advertising program. (a) Retailer's profit. (b) Manufacturer's profit.

consideration to coordinate the supply chain. Based on this, we propose the incentive cooperative advertising mechanism to improve supply chain performance further.

By deriving the equilibrium strategies and making some comparisons under different cases, we obtain the following results: (i) under encroachment, the retailer and the manufacturer may increase or decrease advertising expenditure, which is related with the manufacturer's sell disadvantage $s$ and sequence of quantity decision. With encroachment, the retailer spends more on advertising if the manufacturer's sell disadvantage $s$ is larger than a threshold in most cases. In contrast, the retailer decreases advertising expenses always if the manufacturer commits the selling quantity directly. Different from the retailer, the manufacturer is willing to increases his advertising expenditure always except that they make quantity decisions simultaneously. In that case, the manufacturer cuts down investment on advertising if his sell disadvantage $s$ is relatively high. (ii) under encroachment, both the retailer and the manufacturer may get higher profits, which depends on the manufacturer's sell disadvantage $s$ and their advertising effectiveness. To be specific, a higher $s$ makes it more possible for the retailer to obtain more when encroachment happens. With encroachment, if the manufacturer's advertising effectiveness is relatively high, he is more likely to increase profit. Otherwise, encroachment may hurt him, especially when $s$ is beyond the feasible region; (iv) the centralized advertising decision-making is not always good for both firms. To be specific, the higher the advertising effectiveness of a player, the less likely he is to make centralized advertising decisions. And the proposed incentive cooperative advertising can further increase profits of both firms based on the cooperative advertising program.

Admittedly, this study has some limitations, so the results should be interpreted with caution. However, these findings suggest several interesting directions for further research. Further research can explore whether the results hold if the capacity of the manufacturer is constrained. Under these circumstances, whether it is still more advantageous to give priority to the retailer's orders can be investigated as well.

\section{Appendix A.}

Proof of Proposition 3.1. The backward induction is used to derive the optimal solutions. Thus, the order quantity of the retailer can be obtained at first. The retailer decides order quantity $q_{r}$ to maximize his profit, which yields $q_{r}^{B}=\frac{\left(k_{m} \sqrt{A}+k_{r} \sqrt{a}\right)(v-w) \alpha}{2 v}$. Anticipating this, the manufacturer decides wholesale price to maximize his profit. Solving $\frac{\partial \pi_{m}^{B}}{\partial w}=0$, we can get the wholesale price $w^{B}=\frac{c+v}{2}$. Finally, the manufacturer and the retailer decide the advertising expenditure to maximize $\pi_{m}^{B}$ and $\pi_{r}^{B}$. Substituting the quantity decision $q_{r}^{B}$ and wholesale 
price $w^{B}$ into the function of their profits, we can have the optimal advertising expenditure $A^{B}=\frac{k_{m}^{2}(v-c)^{4} \alpha^{2}}{256 v^{2}}$ and $a^{B}=\frac{k_{r}^{2}(v-c)^{4} \alpha^{2}}{1024 v^{2}}$ by solving $\frac{\partial \pi_{m}^{B}}{\partial A}=0$ and $\frac{\partial \pi_{r}^{B}}{\partial a}=0$.

Proof of Proposition 3.2. The proof is similar to that of Proposition 3.1, so we omit it.

Proof of Proposition 3.3. The proof is similar to that of Proposition 3.1, so we omit it.

Proof of Proposition 3.4. The proof is similar to that of Proposition 3.1, so we omit it.

Proof of Corollary 3.5. According to the equilibrium outcome of the benchmark model and the retailer-led quantity decision model, we can have

$$
\begin{aligned}
p^{R}-p^{B} & =\frac{(3 c+2 s-3 v)}{12} \\
w^{R}-w^{B} & =-\frac{s}{6}<0 \\
r^{R}-r^{B} & =\frac{k_{r}^{2}\left(1024 s^{4}-81(v-c)^{4}\right) \alpha^{2}}{82944 v^{2}} \\
m^{R}-m^{B} & =\frac{k_{m}^{2}\left(-9(v-c)^{4}+4\left(3 c^{2}+7 s^{2}+6 c(s-v)-6 s v+3 v^{2}\right)^{2}\right) \alpha^{2}}{2304 v^{2}} .
\end{aligned}
$$

To ensure that the manufacturer encroachment makes sense, i.e., $q^{R}>0$, the condition should be satisfied $s<\frac{3}{5}(v-c)$. Thus, $p^{R}<p^{B}$. Let $f_{1}=1024 s^{4}-81(v-c)^{4}>0$, we can have $s>\frac{3}{4 \sqrt{2}}(v-c)$. So, we can get that $r^{R}>r^{B}$ when $s>\frac{3}{4 \sqrt{2}}(v-c)$. Otherwise, $r^{R}<r^{B}$ when $s<\frac{3}{4 \sqrt{2}}(v-c)$. For $f_{2}=\left(3 c^{2}+7 s^{2}+6 c(s-v)-6 s v+3 v^{2}\right)$, we have $\frac{\partial f_{2}}{\partial v}=6 v-6 c-6 s \geq 0$. Hence, $f_{2}$ is increasing for any $v \geq c+s$ and the minimum is obtained at $v=c+s$, i.e., $f_{2} \geq 4 s^{2}$. Here, we denote $f_{3}=2\left(3 c^{2}+7 s^{2}+6 c(s-v)-6 s v+3 v^{2}\right)-3(v-c)^{2}$, we can have

$$
\frac{\partial f_{3}}{\partial s}=12 c+28 s-12 v
$$

So $\frac{\partial f_{3}}{\partial s}>0$ in $\left[\frac{3}{7}(v-c), \frac{3}{5}(v-c)\right]$ and $\frac{\partial f_{3}}{\partial s}<0$ in $\left[0, \frac{3}{7}(v-c)\right]$. Hence, $f_{3}$ is decreasing in $\left[0, \frac{3}{7}(v-c)\right]$ and increasing in $\left[\frac{3}{7}(v-c), \frac{3}{5}(v-c)\right]$. Thus, the minimum of $f_{3}$ is obtained at $s=\frac{3}{7}(v-c)$, i.e., $f_{3} \geq \frac{3}{7}(v-c)^{2}$. So, $m^{R}-m^{B}>0$ always.

Thus, Proposition 3.1 can be proven.

Proof of Corollary 3.6. Based on the optimal solutions in the retailer-led scenario, we can have ratio $1=\frac{4 s}{3 v-3 c-s}$ and ratio $2=\frac{3 v-3 c-5 s}{3 v-3 c-s}$. Thus,

$$
\begin{aligned}
& \frac{\partial \text { ratio } 1}{\partial s}=\frac{12(v-c)}{(3 v-3 c-s)^{2}}>0 \\
& \frac{\partial \text { ratio } 2}{\partial s}=\frac{12(c-v)}{(3 v-3 c-s)^{2}}<0 .
\end{aligned}
$$

Hence, the Corollary 3.6 can be proven. 
Proof of Corollary 3.7(i). Based on the equilibrium, the profit difference of the retailer between the benchmark scenario and the retailer-led quantity decision scenario can be give

$$
\begin{aligned}
\pi_{r}^{R}-\pi_{r}^{B}= & \frac{1}{82994 v^{2}} \alpha\left(-81\left(4 k_{m}^{2}+k_{r}^{2}\right)(v-c)^{4} \alpha+s^{4}\left(5376 k_{m}^{2}+1024 k_{r}^{2}\right) \alpha\right. \\
& \left.+s^{3}\left(4608 k_{m}^{2}(c-v) \alpha\right)+s^{2}\left(2304\left(k_{m}^{2}(c-v)^{2} \alpha\right)\right)\right) .
\end{aligned}
$$

Letting $d \pi_{r}^{1}=\pi_{r}^{R}-\pi_{r}^{B}$, we can have

$$
\begin{aligned}
\frac{\partial d \pi_{r}^{1}}{\partial s}= & \frac{1}{82994 v^{2}} \alpha\left(4 s^{3}\left(5376 k_{m}^{2}+1024 k_{r}^{2}\right) \alpha+3 s^{2}\left(4608 k_{m}^{2}(c-v) \alpha\right)\right. \\
& \left.+4608 s\left(k_{m}^{2}(c-v)^{2} \alpha\right)\right) .
\end{aligned}
$$

Letting the part of numerator of $\frac{\partial d \pi_{r}^{1}}{\partial s}$ as

$$
f_{4}=\left(4 s^{3}\left(5376 k_{m}^{2}+1024 k_{r}^{2}\right) \alpha+3 s^{2}\left(4608 k_{m}^{2}(c-v) \alpha\right)+4608 s\left(k_{m}^{2}(c-v)^{2} \alpha\right)\right) .
$$

Obviously, $f_{4}$ is a cubic function of $s$. According to the characteristics of cubic function, we can have the following discriminant function:

$$
\begin{aligned}
\Delta_{1} & =4\left(3\left(4608 k_{m}^{2}(c-v) \alpha\right)\right)^{2}-12\left(4\left(5376 k_{m}^{2}+1024 k_{r}^{2}\right) \alpha\right)\left(4608\left(k_{m}^{2}(c-v)^{2} \alpha\right)\right) \\
& =-28311552 \alpha\left(k_{m}^{2}\left(15 k_{m}^{2}+8 k_{r}^{2}\right)(c-v)^{2} \alpha\right)<0 .
\end{aligned}
$$

So, $f_{4}$ is increasing for any $s<\frac{3}{5}(v-c)$. Moreover, the minimum of $f_{4}=0$ is obtained when $s=0$. Thus, $\frac{\partial d \pi_{r}^{1}}{\partial s} \geq 0$ because both its denominator and numerator are positive within the feasible region, which implies $d \pi_{r}^{1}$ is increasing with $s$ in $\left[0, \frac{3}{5}(v-c)\right]$. When $s=0$ and $s=\frac{3}{5}(v-c)$, we can have $d \pi_{r}^{1}=\frac{\left(-\left(4 k_{m}^{2}+k_{r}^{2}\right)(v-c)^{4} \alpha^{2}\right)}{1024 v^{2}}<0$ and $d \pi_{r}^{1}=\frac{\left.399\left(4 k_{m}^{2}+k_{r}^{2}\right)(c-v)^{2} \alpha\right) \alpha}{640000 v^{2}}>0$, respectively. Moreover, $d \pi_{r}^{1}=\frac{(37-24 \sqrt{2}) k_{m}^{2}(c-v)^{4} \alpha^{2}}{4096 v^{2}}>0$ when $s=\frac{3}{4 \sqrt{2}}(v-c)$. There exists a unique point $\widetilde{s_{1}}<\frac{3}{4 \sqrt{2}}(v-c)$ that we have $d \pi_{r}^{1}=0$, i.e., $\pi_{r}^{R}=\pi_{r}^{B}$.

Thus, the part (i) of Corollary 3.7 can be proven.

Proof of Corollary 3.7(ii). Similarly, we can have the profit difference of the manufacturer between the two scenarios as:

$$
\begin{aligned}
\pi_{m}^{R}-\pi_{m}^{B}= & \frac{1}{6912 v^{2}} \alpha\left(27\left(3 k_{m}^{2}-k_{r}^{2}\right)(v-c)^{4} \alpha+s^{4}\left(588 k_{m}^{2}+448 k_{r}^{2}\right) \alpha\right. \\
& +s^{3}\left(48\left(21 k_{m}^{2}+8 k_{r}^{2}\right)(c-v) \alpha\right)+s^{2}\left(24\left(39 k_{m}^{2}+8 k_{r}^{2}\right)(v-c)^{2} \alpha\right) \\
& \left.+s\left(432\left(k_{m}^{2}(c-v)^{3} \alpha\right)\right)\right) .
\end{aligned}
$$

Letting $d \pi_{m}^{1}=\pi_{m}^{R}-\pi_{m}^{B}$, we can have

$$
\begin{aligned}
\frac{\partial d \pi_{m}^{1}}{\partial s}= & \frac{1}{6912 v^{2}} \alpha^{2}\left(s^{3}\left(2352 k_{m}^{2}+1792 k_{r}^{2}\right)+s^{2}\left(3024 k_{m}^{2}+1152 k_{r}^{2}\right)(c-v)\right. \\
& \left.+s\left(1872 k_{m}^{2}+384 k_{r}^{2}\right)(v-c)^{2}+432 k_{m}^{2}(c-v)^{3}\right) .
\end{aligned}
$$

Letting the part of numerator of $\frac{\partial d \pi_{m}^{1}}{\partial s}$ as

$$
f_{5}=s\left(2352 k_{m}^{2}+1792 k_{r}^{2}\right)+s\left(3024 k_{m}^{2}+1152 k_{r}^{2}\right)(c-v)+s\left(1872 k_{m}^{2}+384 k_{r}^{2}\right)(v-c)+432 k_{m}^{2}(c-v)
$$


$f_{5}$ is also a cubic function of $s$. Similarly, we can have the following discriminant function:

$$
\begin{aligned}
\Delta_{2}= & 4\left(\left(3024 k_{m}^{2}+1152 k_{r}^{2}\right)(c-v)\right)^{2}-12\left(2352 k_{m}^{2}+1792 k_{r}^{2}\right)\left(1872 k_{m}^{2}+384 k_{r}^{2}\right)(v-c)^{2} \\
& =-36864 \alpha^{2}\left(441 k_{m}^{2}+630 k_{m}^{2} k_{r}^{2}+80 k_{r}^{4}\right)(c-v)^{2}<0 .
\end{aligned}
$$

Thus, $f_{5}$ increases monotonically with $s$. And the minimum $f_{5}=432 k_{m}^{2}(c-v)^{3}<0$ is obtained at $s=0$. When $s=\frac{3}{5}(v-c), f_{5}=\frac{2304}{125}\left(6 k_{m}^{2}+11 k_{r}^{2}\right)(v-c)^{3}>0$. As a result, there exist an unique $s=s_{0}$ that we can have $f_{5}=0$. Therefore, $\frac{\partial d \pi_{m}^{1}}{\partial s}<0$ if $s$ in $\left[0, s_{0}\right]$ and $\frac{\partial d \pi_{m}^{1}}{\partial s}>0$ if $s$ in $\left[s_{0}, \frac{3}{5}(v-c)\right]$. Thus, $d \pi_{m}^{1}$ first decreases monotonically and then increases monotonically. When $s=0, d \pi_{m}^{1}=\frac{\left(3 k_{m}^{2}-k_{r}^{2}\right)(c-v)^{4} \alpha^{2}}{256 v^{2}}$. When $s=\frac{3}{5}(v-c)$, $d \pi_{m}^{1}=\frac{\left(399\left(k_{m}^{2}+k_{r}^{2}\right)(c-v)^{4} \alpha^{2}\right)}{16000 v^{2}}>0$. It can be seen that $\frac{\left(3 k_{m}^{2}-k_{r}^{2}\right)(c-v)^{4} \alpha}{256 v^{2}}<0$ when $k_{m}^{2}<\frac{1}{3} k_{r}^{2}$. So, there exist a threshold $\widetilde{s_{2}}$. The manufacturer wins under encroachment, i.e., $d \pi_{m}^{1}=\pi_{m}^{R}-\pi_{m}^{B}>0$, if and only if $s>\widetilde{s_{2}}$. When $k_{m}^{2}>\frac{1}{3} k_{r}^{2}$, the manufacturer is likely to benefit from encroachment when $s$ is relatively low or relatively high.

Proof of Corollary 3.8. The proof is similar to that of Corollary 3.5, so we omit it.

Proof of Corollary 3.9(i). The profit difference between the Manufacturer-led case and the benchmark model can be given as:

$$
d \pi_{r}^{2}=\pi_{r}^{M}-\pi_{r}^{B}=\frac{\alpha^{2}}{1024 v^{2}}\left(k_{r}^{2} f_{6}+k_{m}^{2} f_{7}\right)
$$

where $f_{6}=\left(16 s^{4}-(c-v)^{4}\right)$ and $f_{7}=\left(-4(c-v)^{4}+32 s^{2}\left(c^{2}+2 s^{2}+2 c(s-v)-2 s v+v^{2}\right)\right)$. For any $s<\frac{(v-c)}{2}, f_{6}<0$ always. Similarly, we can prove that $f_{7}$ increases monotonically with $s$ and $f_{7} \leq 0$ for any $s<\frac{(v-c)}{2}$. Thus, $d \pi_{r}^{2}<0$ holds. That is $\pi_{r}^{M}<\pi_{r}^{B}$.

Proof of Corollary 3.9(ii). Similarly, we can have the profit difference of the manufacturer between the two cases as:

$$
\begin{aligned}
d \pi_{m}^{2}= & \pi_{m}^{M}-\pi_{m}^{B}=\frac{1}{256 v^{2}} \alpha^{2}\left(\left(3 k_{m}^{2}-k_{r}^{2}\right)(c-v)^{4}+s^{4}\left(16 k_{m}^{2}+16 k_{r}^{2}\right)\right. \\
& \left.+s^{3}\left(16\left(2 k_{m}^{2}+k_{r}^{2}\right)(c-v)\right)+s^{2}\left(8\left(4 k_{m}^{2}+k_{r}^{2}\right)(c-v)^{2}\right)+s\left(16 k_{m}^{2}(c-v)^{3}\right)\right) .
\end{aligned}
$$

Letting $f_{8}=\frac{\partial d \pi_{m}^{2}}{\partial s}$, we can have

$$
\begin{aligned}
f_{8}= & \frac{\alpha^{2}}{256 v^{2}}\left(4 s^{3}\left(16 k_{m}^{2}+16 k_{r}^{2}\right)+3 s^{2}\left(16\left(2 k_{m}^{2}+k_{r}^{2}\right)(c-v)^{2}\right)+2 s\left(8\left(4 k_{m}^{2}+k_{r}^{2}\right)(c-v)^{2}\right)\right. \\
& \left.+\left(16 k_{m}^{2}(c-v)^{3}\right)\right) .
\end{aligned}
$$

It can be proven that $f_{8}$ increases monotonically with $s$ and there is an unique $s$ within the feasible region to have $f_{8}=0$. Consequently, $d \pi_{m}^{2}$ decreases monotonically firstly and increases monotonically then. When $s=0$, $d \pi_{m}^{2}=\frac{1}{256 v^{2}} \alpha^{2}\left(3 k_{m}^{2}-k_{r}^{2}\right)(c-v)^{4}$. When $s=\frac{(v-c)}{2}, d \pi_{m}^{2}=0$. If $k_{m}^{2}<\frac{1}{3} k_{r}^{2}, d \pi_{m}^{2}<0$ always. If $k_{m}^{2}>\frac{1}{3} k_{r}^{2}$, there exist a threshold $\widetilde{s_{3}}$ to have $d \pi_{m}^{2}=0$. Thus, $d \pi_{m}^{2}>0$ if and only if $k_{m}^{2}>\frac{1}{3} k_{r}^{2}$ and $s<\widetilde{s_{3}}$.

Proof of Corollary 3.10. The proof is similar to that of Corollary 3.5, so we omit it.

Proof of Corollary 3.11(i). The profits difference of the retailer between the two case can be given as:

$$
\begin{aligned}
d \pi_{r}^{3}= & \pi_{r}^{S}-\pi_{r}^{B}=\frac{1}{640000 v^{2}} \alpha^{2}\left(-625\left(4 k_{m}^{2}+k_{r}^{2}\right)(c-v)^{4}+s^{4}\left(23040 k_{m}^{2}+4096 k_{r}^{2}\right)\right. \\
& \left.+s^{3}\left(25600 k_{m}^{2}(c-v)\right)+s^{2}\left(12800 k_{m}^{2}(c-v)^{2}\right)\right) .
\end{aligned}
$$


Similarly, it can be proven that $d \pi_{r}^{3}$ increases monotonically with $s$. When $s=0, d \pi_{r}^{3}=\frac{1}{640000 v^{2}} \alpha^{2}\left(-625\left(4 k_{m}^{2}+k_{r}^{2}\right)(c-v)^{4}\right)<0 ;$ when $s=\frac{5}{7}(v-c), d \pi_{r}^{3}=$ $\frac{\left(2684 k_{m}^{2}+1695 k_{r}^{2}\right)(c-u)^{4} \alpha^{2}}{2458624 u^{2}}>0$.

So, there is a threshold $\widetilde{s_{4}}$ to have $d \pi_{r}^{3}=0$. Thus, $\pi_{r}^{S}>\pi_{r}^{B}$ holds if and only if $s>\widetilde{s_{4}}$.

Proof of Corollary 3.11(ii). Similarly, we can have the profits difference of the manufacturer between the two cases as:

$$
\begin{aligned}
d \pi_{m}^{3}= & \pi_{m}^{S}-\pi_{m}^{B}=\frac{1}{32000 v^{2}} \alpha^{2}\left(125\left(3 k_{m}^{2}-k_{r}^{2}\right)(c-v)^{4}+s^{4}\left(1620 k_{m}^{2}+1152 k_{r}^{2}\right)\right. \\
& \left.+s^{3}\left(80\left(45 k_{m}^{2}+16 k_{r}^{2}\right)(c-v)\right)+s^{2}\left(40\left(95 k_{m}^{2}+16 k_{r}^{2}\right)(c-v)^{2}\right)+s\left(2000 k_{m}^{2}(c-v)^{3}\right)\right) .
\end{aligned}
$$

Letting $f_{9}=\frac{\partial d \pi_{m}^{3}}{\partial s}$, we can prove that $f_{9}$ increases monotonically with $s$. When $s=0, f_{9}=\frac{k_{m}^{2}(c-v)^{3}}{16 v^{2}}<0$; when $s=\frac{5}{7}(v-c), f_{9}=\frac{\left(15 k_{m}^{2}+34 k_{r}^{2}\right)(v-c)^{3}}{1715 v^{2}}>0$. So, there exists an unique $s$ to have $f_{9}=0$. Thus, $d \pi_{m}^{3}$ decreases monotonically first and increases monotonically then. If $s=0, d \pi_{m}^{3}=\frac{\left(3 k_{m}^{2}-k_{r}^{2}\right)(c-v)^{4} \alpha^{2}}{256 u^{2}}$; if $s=\frac{5}{7}(v-c)$, $d \pi_{m}^{3}=\frac{\left(671 k_{m}^{2}-97 k_{r}^{2}\right)(c-v)^{4} \alpha^{2}}{614656 u^{2}}$. Therefore, the results can be obtained according to the properties of the function.

Proof of Corollary 3.12. Based on the optimal solutions, the corollary can be proven easily.

Proof of Proposition 4.1. Backward induction is used to solve the game as well. By maximizing his profit $\pi_{m}^{\mathrm{DA}}$, we can at first generate the optimal quantity decision as $q_{m}^{\mathrm{DA}}=-\frac{q_{r} v+\left(k_{m} \sqrt{\mathrm{A}}+k_{r} \sqrt{\mathrm{a}}\right)(c+s-v) \alpha}{2 v}$. Substituting is into the retailer's profit $\pi_{r}^{\mathrm{DA}}$, we can get the optimal quantity decision of the retailer by solving $\frac{\partial \pi_{r}^{\mathrm{DA}}}{\partial q_{r}}=0$, i.e., $q_{r}^{\mathrm{DA}}=\frac{\left(k_{m} \sqrt{A}+k_{r} \sqrt{a}\right)(c+s+v-2 w) \alpha}{2 v}$. In stage 2, the manufacturer chooses the wholesale price to maximizing his profit, which yields $w^{2 v}=\frac{3 v+3 c-s}{6}$. Finally, the retailer in stage 1 decides his advertising expenditure to maximize his profit according to the subsidy rate $\beta$ and the manufacturer's advertising expenditure $A$, which renders $a^{\mathrm{DA}}=\frac{k_{r}^{2} s^{4} \alpha^{2}}{81 v^{2}(1-\beta)^{2}}$. Anticipating this, the manufacturer determines his subsidy rate and his advertising expenditure simultaneously. By solving $\frac{\partial \pi_{m}^{\mathrm{DA}}}{\partial \beta}=0$ and $\frac{\partial \pi_{m}^{\mathrm{DA}}}{\partial A}=0$ simultaneously, we can obtain

$$
\begin{aligned}
\beta & =\frac{9 c^{2}+18 c s+17 s^{2}-18 c v-18 s v+9 v^{2}}{9 c^{2}+18 c s+25 s^{2}-18 c v-18 s v+9 v^{2}} \\
A^{\mathrm{DA}} & =\frac{k_{m}^{2}\left(3 c^{2}+6 c s+7 s^{2}-6 c v-6 s v+3 v^{2}\right)^{2} \alpha^{2}}{576 v^{2}} .
\end{aligned}
$$

Note that the corresponding Hessian Matrix can ben be given as

$$
H_{1}=\left[\begin{array}{ll}
h_{1} & 0 \\
0 & h_{2}
\end{array}\right]
$$

where $h_{1}=-\frac{k_{m}\left(3 c^{2}+7 s^{2}+6 c(s-v)-6 s v+3 v^{2}\right) \alpha}{48 A^{3 / 2} v}<0$ and $h_{2}=-\frac{k_{r}\left(9 c^{2}+25 s^{2}+18 c(s-v)-18 s v+9 v^{2}\right)^{4} 2 \alpha^{2}}{165888 s^{4} v^{2}}<0$. Thus, the Hessian Matrix is a negative definite matrix. The manufacturer can maximize his profit at $\beta=\frac{9 c^{2}+18 c s+17 s^{2}-18 c v-18 s v+9 v^{2}}{9 c^{2}+18 c s+25 s^{2}-18 c v-18 s v+9 v^{2}}$ and $A^{\mathrm{DA}}=\frac{k_{m}^{2}\left(3 c^{2}+6 c s+7 s^{2}-6 c v-6 s v+3 v^{2}\right)^{2} \alpha^{2}}{576 v^{2}}$.

Proof of Corollary 4.2. Comparing the optimal profits of the manufacturer and the retailer between noncooperative advertising and cooperative advertising under the retailer-led quantity decision scenario, we can 
have

$$
\begin{aligned}
& \pi_{r}^{\mathrm{DA}}-\pi_{r}^{R}=\frac{s^{2} k_{r}^{2}\left(9 c^{2}+18 c s+17 s^{2}-18(c+s) v+9 v^{2}\right) \alpha^{2}}{648 v^{2}} \\
& \pi_{m}^{\mathrm{DA}}-\pi_{m}^{R}=\frac{k_{r}^{2}\left(9 c^{2}+18 c s+17 s^{2}-18(c+s) v+9 v^{2}\right)^{2} \alpha^{2}}{5184 v^{2}}>0 .
\end{aligned}
$$

Letting $f_{10}=\left(9 c^{2}+18 c s+17 s^{2}-18(c+s) v+9 v^{2}\right)$, we can take a derivate of $f_{10}$ with respect to $v$. Hence, we can have $\frac{\partial f_{10}}{\partial v}=-18(c+s)+18 v$. That is $\frac{\partial f_{10}}{\partial v}>0$ when $v>c+s$. Thus, $f_{10}$ is increasing within the feasible region and $f_{10}>8 c 2^{2}>0$. So, $\pi_{m}^{\mathrm{DA}}>\pi_{m}^{R}$.

Thus, the Corollary 4.2 is proven.

Proof of Proposition 4.3. The optimal solutions of the quantity decision and the wholesale price can be derived similarly. The difference is that under the centralized advertising decision-making the manufacturer and the retailer decide the advertising expenditures to maximizing the profit of the whole supply chain $\pi_{s}^{\mathrm{CA}}$. By solving $\frac{\partial \pi_{s}^{\mathrm{CA}}}{\partial A}=0$ and $\frac{\partial \pi_{s}^{\mathrm{CA}}}{\partial a}=0$, we can have $A^{\mathrm{CA}}=\frac{k_{m}^{2}\left(9 c^{2}+18 c s+29 s^{2}-18 c v-18 s v+9 v^{2}\right)^{2} \alpha^{2}}{5184 v^{2}}$ and $a^{\mathrm{CA}}=\frac{k_{r}^{2}\left(9 c^{2}+18 c s+29 s^{2}-18 c v-18 s v+9 v^{2}\right)^{2} \alpha^{2}}{5184 v^{2}}$. And the corresponding Hessian Matrix is a negative definite matrix as well.

Proof of Corollary 4.4. Comparing the optimal profits of the manufacturer and the retailer between cooperative advertising and centralized advertising decision-making under the retailer-led quantity decision scenario, we can have

$$
\begin{aligned}
\pi_{s}^{\mathrm{CA}}-\pi_{s}^{\mathrm{DA}}= & \frac{s^{4}\left(4 k_{m}^{2}+k_{r}^{2}\right) \alpha^{2}}{324 v^{2}}>0 \\
\pi_{r}^{\mathrm{CA}}-\pi_{r}^{\mathrm{DA}}= & \frac{1}{5184 v^{2}} \alpha^{2}\left(s^{4}\left(128 k_{m}^{2}-577 k_{r}^{2}\right)-900 s^{3} k_{r}^{2}(c-v)-774 s^{2} k_{r}^{2}(c-v)^{2}\right. \\
& \left.-324 s k_{r}^{2}(c-v)^{3}-81 k_{r}^{2}(c-v)^{4}\right) \\
\pi_{m}^{\mathrm{CA}}-\pi_{m}^{\mathrm{DA}}= & \frac{1}{5184 v^{2}} \alpha^{2}\left(s^{4}\left(-64 k_{m}^{2}+593 k_{r}^{2}\right)+900 s^{3} k_{r}^{2}(c-v)+774 s^{2} k_{r}^{2}(c-v)^{2}\right. \\
& \left.+324 s k_{r}^{2}(c-v)^{3}+81 k_{r}^{2}(c-v)^{4}\right) .
\end{aligned}
$$

Letting $f_{11}=\left(s^{4}\left(128 k_{m}^{2}-577 k_{r}^{2}\right)-900 s^{3} k_{r}^{2}(c-v)-774 s^{2} k_{r}^{2}(c-v)^{2}-324 s k_{r}^{2}(c-v)^{3}-81 k_{r}^{2}(c-v)^{4}\right)$ and $s=t(v-c)$, where $0<t<\frac{3}{5}$, we can have $f_{11}=128 k_{m}^{2} t^{4}(v-c)^{4}+k_{r}^{2} f_{12}(v-c)^{4}$, where $f_{12}=-81+$ $324 t-774 t^{2}+900 t^{3}-577 t^{4}$. For any $t$ in $\left[0, \frac{3}{5}\right]$, it is easily to get that $f_{13}=\frac{\partial f_{12}}{\partial t}=324-1548 t+2700 t^{2}-2308 t^{3}$. According to the characteristic of the cubic function, we can have the following discriminant function $\Delta_{3}=4\left(2700^{2}-3(-2308)(-1548)\right)=-13713408<0$. Thus, $f_{13}$ is decreasing in $\left[0, \frac{3}{5}\right]$ and the maximum and the minimum are 324 and $-\frac{16416}{125}$. And there is a unique $t_{0}$ to make $f_{13}=\frac{\partial f_{12}}{\partial t}=0$. It means that $f_{12}$ increases firstly and decreases then concerning to $t$. Moreover, it can be proven that the maximum $f_{12}<0$ at $t_{0}$. So, $f_{12}<0$ always. Hence, $f_{11}>0$ when $\frac{k_{m}^{2}}{k_{r}^{2}}>\frac{-f_{12}(v-c)}{128 t}$ and $f_{11}<0$ when $\frac{k_{m}^{2}}{k_{r}^{2}}<\frac{-f_{12}}{128 t^{4}}$. We denote $\delta=\frac{k_{m}}{k_{r}}$ and $\widetilde{\delta_{1}}=\sqrt{\frac{-f_{12}}{128 t^{4}}}$. Note that $\pi_{r}^{\mathrm{CA}}-\pi_{r}^{\mathrm{DA}}>0$ and $\pi_{r}^{\mathrm{CA}}-\pi_{r}^{\mathrm{DA}}<0$ are equal to $f_{11}>0$ and $f_{11}<0$, respectively. Therefore, $\pi_{r}^{\mathrm{CA}}-\pi_{r}^{\mathrm{DA}}>0$ when $\delta>\widetilde{\delta_{1}}$ and $\pi_{r}^{\mathrm{CA}}-\pi_{r}^{\mathrm{DA}}<0$ when $\delta<\widetilde{\delta_{1}}$.

Similarly, the part (iii) of Corollary 4.4 can be proven. And we can have $\widetilde{\delta_{2}}=\sqrt{\frac{f_{14}}{64 t^{4}}}$, where $f_{14}=81-324 t+$ $774 t^{2}-900 t^{3}+593 t^{4}$. Obviously, $\widetilde{\delta_{2}}>\widetilde{\delta_{1}}$ Thus, Corollary 4.4 is proven. 
Proof of Proposition 4.5. Similar to the cooperative advertising program, the quantity decision and the wholesale price under incentive cooperative advertising program can solved backward. Thus, we can generate the quantity decision and the wholesale price as $q_{m}^{\mathrm{IA}}=\frac{\left(k_{m} \sqrt{A}+k_{r} \sqrt{a}\right)(3 v-3 c-5 s) \alpha}{6 v}, q_{r}^{\mathrm{IA}}=\frac{2 s\left(k_{m} \sqrt{A}+k_{r} \sqrt{a}\right) \alpha}{3 v}$ and $w^{\mathrm{IA}}=\frac{1}{6}(3 v+3 c-s)$. According to the higher subsidy rate $\varphi$ and the advertising expenditure $A$ by the manufacturer, the retailer in stage 1 chooses his advertising expenditure $a$ to maximize his profit. Note that $a_{b}=\frac{k_{r}^{2}\left(9 c^{2}+25 s^{2}+18 c(s-v)-18 s v+9 v^{2}\right)^{2} \alpha^{2}}{5184 v^{2}}$ and $\beta_{b}=\frac{9 c^{2}+18 c s+17 s^{2}-18 c v-18 s v+9 v^{2}}{9 c^{2}+18 c s+25 s^{2}-18 c v-18 s v+9 v^{2}}$. That the retailer chooses $a^{\mathrm{IA}} \leq a_{b}$ or $a^{\mathrm{IA}}>a_{b}$ depends on where he can obtain higher profit. So, we should compare the profits under the two cases.

If the retailer chooses the optimal $a^{\mathrm{IA}} \leq a_{b}$, we can generate the optimal $a^{\mathrm{IA}}=a_{b}$ by solving $\frac{\partial \pi_{r}^{\mathrm{IA}}}{\partial a}=0$. Substituting the retailer's advertising expenditure into the manufacturer's profit, we can have the optimal $A^{\mathrm{IA}}=\frac{k_{m}^{2}\left(3 c^{2}+6 c s+7 s^{2}-6 c v-6 s v+3 v^{2}\right)^{2} \alpha^{2}}{576 v^{2}}$ by solving $\frac{\partial \pi_{m}^{\mathrm{IA}}}{\partial A}=0$. As a consequence, the profits of the manufacturer and the retailer under the incentive cooperative advertising program are the same as that under the cooperative advertising program when the retailer chooses the optimal $a^{\mathrm{IA}} \leq a_{b}$, i.e., $\pi_{r}^{\mathrm{IA}}=\pi_{r}^{\mathrm{DA}}$ if $a^{\mathrm{IA}} \leq a_{b}$ and $\pi_{m}^{\mathrm{IA}}=\pi_{m}^{\mathrm{DA}}$ if $a^{\mathrm{IA}} \leq a_{b}$. In this situation, the incentive cooperative advertising program makes no sense. And the profits under the cooperative advertising program is the same as that under the incentive cooperative advertising program.

If the retailer chooses the optimal $a^{I A}>a_{b}$, we can generate the optimal $a^{I A}=\frac{s^{4} k_{r}^{2} \alpha^{2}}{81 v^{2}(-1+\varphi)^{2}}$. For $\frac{s^{4} k_{r}^{2} \alpha^{2}}{81 v^{2}(-1+\varphi)^{2}}>a_{b}$, we can have $\varphi>\beta_{b}=\frac{9 c^{2}+18 c s+17 s^{2}-18 c v-18 s v+9 v^{2}}{9 c^{2}+18 c s+25 s^{2}-18 c v-18 s v+9 v^{2}}$. Anticipating the retailer's advertising decision, the manufacturer determines the higher subsidy rate $\varphi$ and advertising expenditure $A$ to maximize his profit. By solving $\frac{\partial \pi_{m}^{\mathrm{IA}}}{\partial A}=0$ and $\frac{\partial \pi_{m}^{\mathrm{IA}}}{\partial \varphi}=0$, we can obtain optimal $A^{\mathrm{IA}}=\frac{k_{m}^{2}\left(3 c^{2}+6 c s+7 s^{2}-6 c v-6 s v+3 v^{2}\right)^{2} \alpha^{2}}{576 v^{2}}$. For any $\varphi>\beta_{b}$, we can have $\frac{\partial \pi_{m}^{\mathrm{IA}}}{\partial A}=\frac{-24 \sqrt{A} v+k_{m}\left(3 c^{2}+7 s^{2}+6 c(s-v)-6 s v+3 v^{2}\right) \alpha}{24 \sqrt{A} v}$. Obviously, it can be seen that there is no interaction between the higher subsidy rate $\varphi$ and the manufacturer's advertising expenditure $A$. Since the complexity of $\frac{\partial \pi_{m}^{\mathrm{IA}}}{\partial \varphi}$, it is challenging to derive the optimal $\varphi$ analytically. Thus, we first look for the valid ranges of $\varphi$ that the incentive cooperative advertising program is better than the cooperative advertising program. Mathematica 10.2.0.0 was used in our paper to prove the existence of $\varphi$.

Base on the above proof, the incentive cooperative advertising program may make sense only when $a^{\mathrm{IA}}>a_{b}$. Obviously, the retailer chooses the optimal advertising expenditure $a^{\mathrm{IA}}>a_{b}$ if his profit is greater in this case. Hence, the profits gap between the cooperative advertising and the incentive cooperative advertising program can be given as:

$$
\begin{aligned}
\pi_{r}^{\mathrm{IA}}-\pi_{r}^{\mathrm{DA}}= & \frac{1}{5184 v^{2}(1-\varphi)} k_{r}^{2} \alpha^{2}\left(9 c^{2}(-1+\varphi)+18 c(s-v)(-1+\varphi)-18 s v(-1+\varphi)\right. \\
& \left.+9 v^{2}(-1+\varphi)+s^{2}(-17+25 \varphi)\right)^{2} \\
\pi_{m}^{\mathrm{IA}}-\pi_{m}^{\mathrm{DA}}= & \frac{1}{5184 v^{2}(-1+\varphi)^{2}} k_{r}^{2} \alpha^{2} f_{15} f_{16}
\end{aligned}
$$

where

$$
f_{15}=-9 c^{2}-17 s^{2}-18 c(s-v)+18 s v-9 v^{2}+\left(9 c^{2}+25 s^{2}+18 c(s-v)-18 s v+9 v^{2}\right) \varphi
$$

and

$$
\begin{aligned}
f_{16}= & 18 c^{2}+42 s^{2}+36 c(s-v)-36 s v+18 v^{2}+\left(-27 c^{2}-75 s^{2}-54 c(s-v)+54 s v-27 v^{2}\right) \varphi \\
& +\left(9 c^{2}+25 s^{2}+18 c(s-v)-18 s v+9 v^{2}\right) \varphi^{2} .
\end{aligned}
$$

Obviously, $\pi_{r}^{\mathrm{IA}}-\pi_{r}^{\mathrm{DA}}>0$ for any $\varphi$ in $[0,1]$. Similar to previous proof, we can have $f_{17}=9 c^{2}+17 s^{2}+$ $18 c(s-v)-18 s v+9 v^{2}>0$ always. Thus, $f_{15}=-f_{17}+\left(f_{17}+8 s^{2}\right) \varphi>0$ always when $\varphi>\beta_{b}=\frac{f_{17}}{\left(f_{17}+8 s^{2}\right)}$. 
Similarly, we can have $f_{18}=18 c^{2}+42 s^{2}+36 c(s-v)-36 s v+18 v^{2}>0$ always. For any $\varphi \epsilon\left[\beta_{b}, 1\right]$, we can have $f_{16}>0$ when $\varphi \epsilon\left[\beta_{b}, \widetilde{\varphi_{1}}\right]$, where $\widetilde{\varphi_{1}}=\frac{3\left(f_{17}+8 s^{2}\right)-\sqrt{9\left(f_{17}+8 s^{2}\right)^{2}-4\left(f_{17}+8 s^{2}\right) f_{18}}}{2\left(f_{17}+8 s^{2}\right)}$. Obviously, $f_{18}<2\left(f_{17}+8 s^{2}\right)$. Thus, $9\left(f_{17}+8 s^{2}\right)^{2}-4\left(f_{17}+8 s^{2}\right) f_{18}>9\left(f_{17}+8 s^{2}\right)^{2}-8\left(f_{17}+8 s^{2}\right)^{2}>0$. Moreover, $\widetilde{\varphi_{1}}<1$. Hence, $\pi_{m}^{\mathrm{IA}}-\pi_{m}^{\mathrm{DA}}>0$ is equal to $f_{16}>0$, i.e., $\varphi \in\left[\beta_{b}, \widetilde{\varphi_{1}}\right]$.

As a consequence, we can know that both firms can get higher profits if $\varphi \in\left[\beta_{b}, \widetilde{\varphi_{1}}\right]$. If the optima subsidy rate $\varphi \in\left[\beta_{b}, \widetilde{\varphi_{1}}\right]$, the incentive cooperative advertising program can indeed further improve the profits of the retailer and the manufacturer. There exists a local optimal $\varphi$ and $m^{\mathrm{IA}}$ if and only if the corresponding Hessian Matrix is a negative definite matrix and the following conditions are satisfied.

$$
\left\{\begin{array}{l}
\frac{\partial \pi_{m}^{\mathrm{IA}}}{\partial \varphi^{\mathrm{A}}}=0 \\
\frac{\partial \pi_{m}^{\mathrm{IA}}}{\partial A}=0 \\
\beta_{b}<\varphi<\widetilde{\varphi_{1}}
\end{array} .\right.
$$

Note that we can have the Hessian Matrix as

$$
H_{2}=\left[\begin{array}{ll}
h_{3} & 0 \\
0 & h_{4}
\end{array}\right]
$$

where $h_{3}=-\frac{k_{m}\left(3 c^{2}+7 s^{2}+6 c(s-v)-6 s v+3 v^{2}\right) \alpha}{48 A^{3 / 2} v}<0$ and $h_{4}=-\frac{s^{2} k_{r}^{2} \alpha^{2}}{162 v^{2}(-1+\varphi)^{4}}\left(f_{19}+\left(\left(f_{17}+8 s^{2}\right)\right) \varphi\right)$. Here, $f_{19}=-9 c^{2}-13 s^{2}-18 c(s-v)+18 s v-9 v^{2}$. For any $\varphi>\beta_{b},\left(f_{19}+\left(\left(f_{17}+8 s^{2}\right)\right) \varphi\right)>0$ always. Hence, $h_{4}<0$. Therefore, the extreme condition is satisfied. Mathematica 10.2.0.0 was used in our paper to solve the problem (A.1) and prove the existence of the solution. Due to the complexity of the expression, $\varphi^{*}$ is used to represent the optimal subsidy rate.

Thus, the proposition can be proven.

Acknowledgements. The authors declare no conflict of interest regarding the publication of this paper. The research was supported by the National Natural Science Foundation of China (No:71571131) and supported by Tianjin University Innovation Fund.

\section{REFERENCES}

[1] A. Arya and B. Mittendorf, The changing face of distribution channels: partial forward integration and strategic investments. Prod. Oper. Manage. 22 (2013) 1077-1088.

[2] G. Aust and U. Buscher, Vertical cooperative advertising and pricing decisions in a manufacturer-retailer supply chain: a game-theoretic approach. Eur. J. Oper. Res. 223 (2012) 473-482.

[3] R. Batarfi, M.Y. Jaber and S.M. Aljazzar, A profit maximization for a reverse logistics dual-channel supply chain with a return policy. Comput. Ind. Eng. 106 (2017) 58-82.

[4] B. Bao, J. Ma and M. Goh, Short- and long-term repeated game behaviours of two parallel supply chains based on government subsidy in the vehicle market. Int. J. Prod. Res. (2020) 1-24.

[5] M. Bergen and G. John, Understanding cooperative advertising participation rates in conventional channels. J. Marketing Res. 34 (1997) 357-369.

[6] P.D. Berger, J. Lee and B.D. Weinberg, Optimal cooperative advertising integration strategy for organizations adding a direct online channel. J. Oper. Res. Soc. 57 (2006) 920-927.

[7] G.G. Cai, Channel selection and coordination in dual-channel supply chains. J. Retail. 86 (2010) 22-36.

[8] J. Chaab and M. Rasti-Barzoki, Cooperative advertising and pricing in a manufacturer-retailer supply chain with a general demand function: a game-theoretic approach. Comput. Ind. Eng. 99 (2016) 112-123.

[9] T.H. Chen, Effects of the pricing and cooperative advertising policies in a two-echelon dual-channel supply chain. Comput. Ind. Eng. 87 (2015) 250-259.

[10] J. Chen, L. Liang, D.Q. Yao and S. Sun, Price and quality decisions in dual-channel supply chains. Eur. J. Oper. Res. 259 (2017) 935-948.

[11] W.K. Chiang, D. Chhajed and J.D. Hess, Direct marketing indirect profits: a strategic analysis of dual-channel supply-chain design. Manage. Sci. 49 (2003) 1-20.

[12] S. Ghadimi, F. Szidarovszky, R.Z. Farahani and A. Khiabani, Coordination of advertising in supply chain management with cooperating manufacturer and retailers. IMA J. Manage. Math. 24 (2013) 1-19. 
[13] A. Ha, X. Long and J. Nasiry, Quality in supply chain encroachment. Manuf. Serv. Oper. Manage. 18 (2016) $280-298$.

[14] X. He, A. Krishnamoorthy, A. Prasad and S.P. Sethi, Co-op advertising in dynamic retail oligopolies. Decis. Sci. 43 (2012) $73-106$.

[15] L. Hsiao and Y.J. Chen, Strategic motive for introducing internet channels in a supply chain. Prod. Oper. Manage. 23 (2014) $36-47$.

[16] M.F. Hung and T.H. Huang, Dynamic demand for residential electricity in Taiwan under seasonality and increasing-block pricing. Energy Econ. 48 (2015) 168-177.

[17] H. Jafari, S.R. Hejazi and M. Rasti-Barzoki, Pricing decisions in dual-channel supply chain with one manufacturer and multiple retailers: a game-theoretic approach. RAIRO:OR 51 (2017) 1269-1287.

[18] S. Kapner, How the Web drags on some retailers. Wall Street Journal (2014), available from: http://www.wsj.com/articles/ how-the-web-drags-on-some-retailers-1417477790.

[19] S. Karray, Periodicity of pricing and marketing efforts in a distribution channel. Eur. J. Oper. Res. 228 (2013) $635-647$.

[20] M. Kunter, Coordination via cost and revenue sharing in manufacturer-retailer channels. Eur. J. Oper. Res. 216 (2012) $477-486$.

[21] G. Li, L. Zhang, X. Guan and J. Zheng, Impact of decision sequence on reliability enhancement with supply disruption risks Transp. Res. Pt. e-Logist Transp. Rev. 90 (2015) 25-38.

[22] G. Li, L. Li and J. Sun, Pricing and service effort strategy in a dual-channel supply chain with showrooming effect. Transp. Res. Pt. e-Logist. Transp. Rev. 126 (2019) 32-48.

[23] F. Lu, W. Tang, G. Liu and J. Zhang, Cooperative advertising: A way escaping from the prisoner's dilemma in a supply chain with sticky price. Omega Int. J. Manage. 86 (2019) 87-106.

[24] J. Ma, Y. Hou, W. Yang and Y. Tian, A time-based pricing game in a competitive vehicle market regarding the intervention of carbon emission reduction. Energy Policy. 142 (2020) 111440.

[25] J. Ma, F. Zhang and H. Jiang, Dynamic pricing game under different channel power structures in a closed-loop supply chain. Int. J. Bifurcation Chaos. 30 (2020) 2050052.

[26] J. Ru, R. Shi and J. Zhang, Does a store brand always hurt the manufacturer of a competing national brand? Prod. Oper. Manage. 24 (2015) 272-286.

[27] S.P. Sethi, A. Prasad and X. He, Optimal advertising and pricing in a new-product adoption model. J. Optim. Theory Appl. 139 (2008) 351-360.

[28] M.M. Seyedesfahani, M. Biazaran and M. Gharakhani, A game theoretic approach to coordinate pricing and vertical co-op advertising in manufacturer-retailer supply chains. Eur. J. Oper. Res. 211 (2011) 263-273.

[29] R. Shoeleh, M. Seifbarghy and D. Pishva, Modelling pricing vertical co-op advertising and quality improvement in a noncooperative three-echelon supply chain using game theory approach. RAIRO:OR 53 (2019) 1937-1965.

[30] A.A. Taleizadeh, K. Govindan and N. Ebrahimi, The effect of promotional cost sharing on the decisions of two-level supply chain with uncertain demand. Ann. Oper. Res. 290 (2020) 747-781.

[31] Y. Tian, J. Ma, L. Xie, T. Koivumäki and V. Seppänen, Coordination and control of multi-channel supply chain driven by consumers' channel preference and sales effort. Chaos Solitons Fractals. 132 (2020) 109576.

[32] A.A. Tsay and N. Agrawal, Channel conflict and coordination in the e-commerce age. Prod. Oper. Manage. 13 (2004) 93-110.

[33] J. Xie and J.C. Wei, Coordinating advertising and pricing in a manufacturer-retailer channel. Eur. J. Oper. Res. 197 (2009) $785-791$.

[34] L. Xie, J. Ma and M. Goh, Supply chain coordination in the presence of uncertain yield and demand. Int. J. Prod. Res. (2020) $1-17$.

[35] R. Yan, Z. Cao and Z. Pei, Manufacturer's cooperative advertising demand uncertainty and information sharing. J. Bus. Res. 69 (2015) 709-717.

[36] W. Yan, Y. Xiong, J. Chu, G. Li and Z. Xiong, Clicks versus Bricks: the role of durability in marketing channel strategy of durable goods manufacturers. Eur. J. Oper. Res. 265 (2017) 909-918.

[37] J. Yang, J. Xie, X. Deng and H. Xiong, Cooperative advertising in a distribution channel with fairness concerns. Eur. J. Oper. Res. 227 (2013) 401-407.

[38] J. Yue, J. Austin, M.C. Wang and Z. Huang, Coordination of cooperative advertising in a two-level supply chain when manufacturer offers discount. Eur. J. Oper. Res. 168 (2006) 65-85.

[39] J. Zhang and J. Xie, A game theoretical study of cooperative advertising with multiple retailers in a distribution channel. J. Syst. Sci. Syst. Eng. 21 (2011) 37-55.

[40] J. Zhang, S. Li, S. Zhang and R. Dai, Manufacturer encroachment with quality decision under asymmetric demand information. Eur. J. Oper. Res. 273 (2019) 217-236.

[41] Z. Zhang, W. Cai and X. Feng, How do urban households in China respond to increasing block pricing in electricity? Evidence from a fuzzy regression discontinuity approach. Energy Policy 105 (2017) 161-172.

[42] T. Zhang, X. Guo, J. Hu and N. Wang, Cooperative advertising models under different channel power structure. Ann. Oper. Res. 291 (2020) 1103-1125.

[43] L. Zhao, J. Zhang and J. Xie, Impact of demand price elasticity on advantages of cooperative advertising in a two-tier supply chain. Int. J. Prod. Res. 54 (2016) 2541-2551.

[44] Y.-W. Zhou, J. Li and Y. Zhong, Co-operative advertising and ordering policies in a two-echelon supply chain with risk-averse agents. Omega Int. J. Manage. 75 (2018) 97-117. 